\title{
Lesion analysis of the brain areas involved in language comprehension
}

\author{
Nina F. Dronkers ${ }^{\mathrm{a}, \mathrm{b}, *}$, David P. Wilkins ${ }^{\mathrm{a}}$, Robert D. Van Valin Jr. ${ }^{\mathrm{c}}$, \\ Brenda B. Redfern ${ }^{\mathrm{a}}$, Jeri J. Jaeger ${ }^{\mathrm{c}}$ \\ ${ }^{a}$ VA Northern California Health Care System, Martinez, CA, USA \\ ${ }^{\mathrm{b}}$ University of California, Davis, Davis, CA, USA \\ ${ }^{\mathrm{c}}$ University at Buffalo, State University of New York, Buffalo, NY, USA
}

Received 2 April 2002; revised 14 February 2003; accepted 14 November 2003

\begin{abstract}
The cortical regions of the brain traditionally associated with the comprehension of language are Wernicke's area and Broca's area. However, recent evidence suggests that other brain regions might also be involved in this complex process. This paper describes the opportunity to evaluate a large number of brain-injured patients to determine which lesioned brain areas might affect language comprehension. Sixty-four chronic left hemisphere stroke patients were evaluated on 11 subtests of the Curtiss-Yamada Comprehensive Language Evaluation - Receptive (CYCLE-R; Curtiss, S., \& Yamada, J. (1988). Curtiss-Yamada Comprehensive Language Evaluation. Unpublished test, UCLA). Eight right hemisphere stroke patients and 15 neurologically normal older controls also participated. Patients were required to select a single line drawing from an array of three or four choices that best depicted the content of an auditorily-presented sentence. Patients' lesions obtained from structural neuroimaging were reconstructed onto templates and entered into a voxel-based lesion-symptom mapping (VLSM; Bates, E., Wilson, S., Saygin, A. P., Dick, F., Sereno, M., Knight, R. T., \& Dronkers, N. F. (2003). Voxel-based lesion-symptom mapping. Nature Neuroscience, 6(5), 448-450.) analysis along with the behavioral data. VLSM is a brain-behavior mapping technique that evaluates the relationships between areas of injury and behavioral performance in all patients on a voxel-by-voxel basis, similar to the analysis of functional neuroimaging data. Results indicated that lesions to five left hemisphere brain regions affected performance on the CYCLE-R, including the posterior middle temporal gyrus and underlying white matter, the anterior superior temporal gyrus, the superior temporal sulcus and angular gyrus, mid-frontal cortex in Brodmann's area 46, and Brodmann's area 47 of the inferior frontal gyrus. Lesions to Broca's and Wernicke's areas were not found to significantly alter language comprehension on this particular measure. Further analysis
\end{abstract}

\footnotetext{
* Corresponding author. Center for Aphasia and Related Disorders, VA Northern California Health Care System, 150 Muir Road, Martinez, CA 94553, USA. Tel.: + 1-925-372-2925; fax: + 1-925-372-2553.

E-mail address: dronkers@ucdavis.edu (N.F. Dronkers).
} 
suggested that the middle temporal gyrus may be more important for comprehension at the word level, while the other regions may play a greater role at the level of the sentence. These results are consistent with those seen in recent functional neuroimaging studies and offer complementary data in the effort to understand the brain areas underlying language comprehension.

(C) 2004 Elsevier B.V. All rights reserved.

Keywords: Lesion analysis; Brain areas; Language comprehension; Aphasia

\section{Introduction}

Early work concerning the brain areas involved in language comprehension focused on the deficits observed in brain-injured aphasic patients and the correlation of these deficits with regions of injury in the brain. Recent advances in both structural and functional neuroimaging capabilities have afforded a new means by which earlier neural models of language comprehension can be evaluated. Yet, there has been a paucity of lesion studies that have fully exploited this new technology in defining a more precise role for individual brain areas within the left peri-Sylvian region. This is partly due to the difficulty in recruiting adequate numbers of patients to effectively examine such brain-behavior relationships. More importantly, lesion studies have not had an effective statistically-based tool with which to analyze these data in a way that allows them to explore discrete regions.

This paper will attempt to bridge that gap by utilizing a new method of lesion analysis to explore the brain areas involved in language comprehension in a large number of patients. This technique, designed to be more commensurate with the functional imaging work, was applied to data from a rigidly-screened group of 64 left hemisphere stroke patients, uniform in their handedness, native language, and neurological and psychiatric histories, who underwent the same extensive language and structural neuroimaging evaluations. This large cohort adds a perspective that functional neuroimaging studies, which look at regional activations in normal brains, cannot offer, i.e. the opportunity to examine the effects the absence of these brain areas has on the language comprehension system. Ultimately, findings from both lesion and functional imaging studies would need to converge before an optimal theory of language comprehension in the brain can be realized.

When one thinks of language comprehension, the brain area that first comes to mind is Wernicke's area in the posterior temporal lobe. This is because patients with Wernicke's aphasia have profound language comprehension deficits and often find it difficult to understand even the simplest phrases (Benson \& Ardila, 1996; Goodglass, 1993). Those with Broca's aphasia were not originally thought to have a comprehension disorder (Broca, 1861), but were later shown to have difficulty at the sentence level, particularly with sentences requiring the processing of complex morphosyntactic structures (Berndt \& Caramazza, 1980; Caramazza \& Zurif, 1976; Schwartz, Saffran, \& Marin, 1980; Zurif, Caramazza, \& Meyerson, 1972).

The idea that either a posterior or an anterior lesion could affect aspects of comprehension suggests that it is a more widely distributed process. Functional neuroimaging studies have come to capitalize on this idea by studying normal subjects performing language comprehension tasks under different conditions. In addition to 
Broca's and Wernicke's areas (Brodmann's areas (BA) 44/45 and posterior BA22, respectively), a number of other left hemisphere cortical regions have emerged in auditory word and sentence recognition studies. These include frontal BA 9 and 47 (e.g. Binder, Frost, Hammeke, Rao, \& Cox, 1996; Muller et al., 1997; Schlosser, Aoyagi, Fulbright, Gore, \& McCarthy, 1998), parietal area 39 (e.g. Binder et al., 1996; Perani et al., 1996), and temporal areas 20, 21, and 42 (e.g. Binder et al., 1996; Grady et al., 1997) as well as the anterior portion of area 22 (e.g. Friederici, Meyer, \& von Cramon, 2000; Mazoyer et al., 1993). The question now is whether lesion analysis can concur with the same brainlanguage relationships if an appropriate and comparable method could be found.

More than a decade ago, we began the systematic collection of language and neuropsychological data on a rigidly-selected group of chronic stroke patients referred to our Center for Aphasia and Related Disorders. At the time we began accumulating data, the most viable measure of language comprehension for aphasic patients that covered the broadest range of word, phrase, and sentence types was the Curtiss-Yamada Comprehensive Language Evaluation - Receptive measures (CYCLE-R) (Curtiss \& Yamada, 1988). This test reflected developmental trends in language acquisition from age 2 to 9 , and did not require a verbal response that could hinder performance in aphasic or speech apraxic patients. Over time, we were able to collect CYCLE-R data on a large number of left hemisphere stroke patients who had also undergone structural neuroimaging and whose lesions were computer-reconstructed for further analysis.

In initial presentations of this endeavor (Dronkers, Wilkins, Van Valin, Redfern, \& Jaeger, 1994a,b, 1996), we used a lesion overlay method to explore areas that might be involved in sentence comprehension. One novel finding concerned the involvement of the anterior portion of Brodmann's area 22 in the anterior superior temporal gyrus (STG). We originally thought this area was related to the comprehension of elaborated morphosyntactic structures, as patients with deficits on the more difficult sentence types of the CYCLE-R were all seen to have lesions involving this region. The present study examines this area more closely and amends this role to some degree.

Since that time, the lesion overlay method for the analysis of this type of data has been superceded by a technique newly available to lesion analysis known as voxel-based lesionsymptom mapping (VLSM; Bates et al., 2003). Past lesion studies have typically used one of two methodologies. The first is to group patients on the basis of lesions to a particular brain region and then test for differences between these patients and a control group (e.g. Chao \& Knight, 1998; Friedrich, Egly, Rafal, \& Beck, 1998). The second is to begin by defining a behavior and then to overlap the lesions of those patients to find a common area of injury (e.g. Dronkers, 1996; Kertesz, 1979). While these methods have been useful in offering information about the relationships between specific brain areas and certain behavioral functions, valuable information is sometimes lost if patients or behaviors do not meet certain criteria and must be discarded. VLSM avoids such losses. All continuous behavioral data are statistically analyzed on a voxel-by-voxel basis much as in functional imaging research. This also makes the results between these two literatures more compatible.

In the current study, we evaluated CYCLE-R performance of 64 single left hemisphere stroke patients using the more powerful, statistically-based VLSM method. Computerized lesion reconstructions were entered into the VLSM analysis along with patients' CYCLE-R 
data to evaluate if lesions in specific voxels might influence CYCLE-R performance. The goal was to determine if specific brain regions could be identified that, when lesioned, affected performance on a language comprehension task. We sought to explore several questions, including: What can a statistically-based lesion analysis reveal about the brain areas involved in language comprehension? How do these areas compare to those found in the functional imaging literature? How might each area participate in comprehension? How do these areas relate to each other? Are these areas specific to language or are they shared with other cognitive functions? This study only begins to answer some of these questions. The complexity of language comprehension necessarily dictates that numerous processes and brain areas must be interacting in elaborate ways to achieve this remarkable phenomenon. No single lesion or functional imaging study can provide the definitive answer, though each can contribute to the discussion.

For our contribution, we envision a model that assumes that the brain networks important for lower level functions such as word comprehension feed into networks that support higher level functions such as sentence comprehension. Such an incremental recruitment of brain areas follows from the logic that natural language sentence comprehension depends upon word comprehension, and any brain areas found to support sentences must also depend upon brain areas found to support words if a complete interpretation is to be made. The developing model also assumes that while certain brain areas might be specific to language, higher-level language functions must also interact with other cognitive skills such as executive functioning and short-term verbal memory. Thus, different levels of structural complexity from words to complex sentences are expected to engage distinct regional brain networks while at the same time interacting with other regional networks to effect language comprehension.

It is for these reasons that we chose a sentence comprehension task to explore the brain areas that might contribute to language comprehension from the word level to the level of complex syntax. The use of this measure is described herein. Since excellent reviews on the brain areas contributing to language comprehension can be found elsewhere in the literature (e.g. Cabeza \& Nyberg, 2000; Grodzinsky, 2000; Kaan \& Swaab, 2002), we will wait until the discussion section of our paper (Section 4) to introduce other research as it pertains to the specific findings of the present study. At that time, we will also discuss how our findings merge with those from functional imaging.

\section{Methods}

\subsection{Participants}

Sixty-four left hemisphere-injured (LH) chronic stroke patients, eight right hemisphere-injured (RH) chronic stroke patients, and 15 neurologically normal older controls participated in the study. All were right-handed, monolingual, native English speakers with no history of prior neurologic or psychiatric conditions. Patients suffered a single cerebrovascular accident involving the middle cerebral artery with lesions verified by CT or MR imaging. The RH patients were included to ensure that task performance was not 
affected merely by the presence of cortical injury. Crossed aphasic patients and those with dementing illness were excluded from the study to avoid confounding variables.

LH patients ranged in age from 31 to 80 years (mean 61.5), in time post onset from the stroke from 1 to 20.5 years (mean 4.8), and in education from 5 to 20 years (mean 14.3). Fifteen LH patients were female while the rest were male. RH patients ranged in age from 47 to 77 years (mean 62.5), in time post onset from 1.1 to 16 years (mean 7.5), and in education from 7 to 17 years (mean 13.0). One of these patients was female while the rest were male. Older control participants (seven female, eight male) ranged in age from 47 to 80 years (mean 66.6) and in education from 7 to 20 years (mean 15.1). Age and education for the patients and controls did not differ from each other, nor did the time post onset for the two patient groups. These and other data on each of the brain-injured patients can be found in Table 1.

All patients were assessed with the Western Aphasia Battery (WAB; Kertesz, 1982) to determine their chronic aphasia classification. Forty-six of the LH patients were classified as aphasic, while the remaining 18 tested within normal limits (WNL). Most of these WNL patients still showed clinical signs of word-finding difficulty. Of the 46 patients who tested as aphasic on the WAB, 16 were classified with Broca's aphasia, six with Wernicke's aphasia, 12 with Anomic aphasia, eight with Conduction aphasia, and one with Global aphasia, while the remaining three were unclassifiable per WAB criteria. These LH aphasic patients ranged in WAB Aphasia Quotient (AQ) scores from 10.7 to 92.6 with a mean of 57.68 while the LH WNL patients ranged from 94.2 to 100 with a mean of 97.16 . The eight RH patients did not demonstrate any evidence of aphasia, nor complain of any past language difficulty. Their WAB AQ scores ranged from 97 to 100, WNL. WAB subtest and AQ scores with resultant aphasia classifications can also be found in Table 1 .

\subsection{The Curtiss-Yamada Comprehensive Language Evaluation}

All 72 patients were administered receptive subtests from the CYCLE-R (Curtiss $\&$ Yamada, 1988). The results from 11 of the subtests were selected for analysis and included Simple Declaratives, Possession, Active Voice Word Order, Double Embedding, Agentless Passive, Agentive Passive, Subject Relative Clauses, Object Clefting, Object (O-S) Relative Clauses (main clause object is the subject of the relative clause), Negative Passive, and Object (O-O) Relative Clauses (main clause object is the object of the relative clause). These subtests exemplified a range of declarative sentence types from simple intransitive sentences to morphosyntactically more complex sentences as can be seen by the examples in Table 2. Complexity was determined by independent linguistic analyses and by findings in the literature concerning the comprehension of different sentence types by aphasic patients (e.g. Caplan, 1992; Caplan, Baker, \& Dehaut, 1985). In addition, linguistic complexity is reflected in the developmental range of ages at which a sample of AmericanEnglish-speaking children were found to pass the individual subtests (achieving a score of $80 \%$ or better; Curtiss \& Yamada, 1988). These ages are also provided in Table 2. Normal older controls were administered only the subtests for age levels 6 through 9 due to time constraints and because it was found that the earlier tests were too easy for this group.

All of the subtests required that the participants listen to a sentence presented auditorily by the examiner and select the picture that matched the meaning of the sentence from 
Table 1

Destern Aphasia Battery and Boston Naming Test scores for each study patient

BNT

$\begin{array}{lllllllllll}\begin{array}{l}\text { Age at } \\ \text { testing }\end{array} & \begin{array}{l}\text { Years } \\ \text { post } \\ \text { onset }\end{array} & \text { Education } & \text { Gender } & \begin{array}{l}\text { WAB aphasia } \\ \text { type }\end{array} & \begin{array}{l}\text { WAB AQ } \\ (\max =100)\end{array} & \begin{array}{l}\text { WAB } \\ \text { Fluency } \\ (\max =10)\end{array} & \begin{array}{l}\text { WAB Auditory } \\ \text { Comprehension } \\ (\max =10)\end{array} & \begin{array}{l}\text { WAB } \\ \text { Repetition } \\ (\max =10)\end{array} & \begin{array}{l}\text { WAB } \\ (\max =10)\end{array} & \begin{array}{l}\text { BNT } \\ \text { Spontaneous } \\ \text { Correct } \\ (\max =60)\end{array} \\ \end{array}$

$(\max =60)$

Left hemisphere-injured patients

ANR $\quad 61 \quad 4 \quad 10$

$\begin{array}{llll}\text { ANS } & 76 & 1 & 12 \\ \text { ANW } & 71 & 6.5 & 15\end{array}$

$\begin{array}{llll}\text { ANS } & 76 & 1 & 12 \\ \text { ANW } & 71 & 6.5 & 15\end{array}$

$\begin{array}{llll}\text { ARO } & 64 & 11.9 & 8\end{array}$

$\begin{array}{lrrr}\text { AUS } & 37 & 1.8 & 16\end{array}$

$\begin{array}{llll}\text { BAO } & 76 & 6.3 & 20\end{array}$

$\begin{array}{llll}\mathrm{BIE} & 31 & 1.2 & 13 \\ \mathrm{BIM} & 64 & 8.4 & 14\end{array}$

$\begin{array}{llll}\text { BIM } & 64 & 8.4 & 14\end{array}$

$\begin{array}{llll}\text { BOJ } & 50 & 1.4 & 16\end{array}$

$\begin{array}{llll}\text { CAW } & 58 & 9.6 & 16\end{array}$

$\begin{array}{llll}\text { CLI } & 64 & 3 & 14 \\ \text { COJ } & 68 & 6.1 & 16\end{array}$

$\begin{array}{llll}\text { COJ } & 68 & 6.1 & 16 \\ \text { COM } & 63 & 1.8 & 12\end{array}$

$\begin{array}{lllr}\text { DOR } & 59 & 7.3 & 5\end{array}$

DUD $\quad 55 \quad 1.5 \quad 13$

DUJ $\quad 65 \quad 6.6 \quad 20$

$\begin{array}{llll}\text { ELE } & 68 & 1.3 & 15\end{array}$

EVE $\quad 74 \quad 1.1 \quad 16$

$\begin{array}{llll}\text { FAD } & 46 & 2.0 & 16\end{array}$

$\begin{array}{llll}\text { FAG } & 67 & 8.6 & 14\end{array}$

$\begin{array}{llll}\text { FLA } & 56 & 5.3 & 11\end{array}$

$\begin{array}{llll} & 50 & 4.6 & 19\end{array}$

$\begin{array}{llll}\text { GEJ } & 45 & 1.4 & 12\end{array}$

$\begin{array}{llll}\text { GRW } & 80 & 1.2 & 13\end{array}$

$\begin{array}{llll}\text { HAJ } & 63 & 9.8 & 17\end{array}$

$\begin{array}{llll}\text { HEE } & 72 & 4.2 & 7\end{array}$

$\begin{array}{lcr}\text { Conduction } & 87.5 & 10 \\ \text { Anomic } & 66.7 & 8 \\ \text { WNL } & 96.0 & 9 \\ \text { WNL } & 99.6 & 10 \\ \text { WNL } & 100 & 10 \\ \text { Wernicke's }^{\mathrm{a}} & 34.4 & 8 \\ \text { Unclassifiable }^{\mathrm{a}} & 68.3 & 4 \\ \text { Broca's } & 20.7 & 0 \\ \text { WNL } & 98.6 & 10 \\ \text { WNL } & 97.6 & 10 \\ \text { Broca's } & 28.5 & 3 \\ \text { Anomic } & 86.7 & 6 \\ \text { Anomic } & 87.8 & 9 \\ \text { Anomic } & 87.4 & 9 \\ \text { Broca's } & 18.9 & 0 \\ \text { Anomic } & 90.9 & 9 \\ \text { WNL } & 96.3 & 9 \\ \text { WNL }^{\mathrm{b}} & 98.8 & 10 \\ \text { Broca's } & 54.3 & 4 \\ \text { Unclassifiable } & 70 & 4 \\ \text { Anomic } & 89.4 & 9 \\ \text { Anomic } & 88.5 & 8 \\ \text { WNL } & 94.2 & 9 \\ \text { Conduction } & 82.6 & 9 \\ \text { Wernicke's }_{\text {Anomic }} & 41.7 & 8 \\ \text { Anomic } & 83.6 & 6 \\ & 91.0 & 9\end{array}$

9.75
8.35
10
10
10
3.5
8.65
6.55
10
10
6.35
9.75
9.8
8
6.45
9.55
9.85
10
8.05
9.5
9.6
9.65
9.4
9.65
6.15
8.5
9.9

6.1
7
9.8
10
10
0.3
4.3
0.8
10
9.2
0.6
9.9
7.8
10
0.8
10
10
10
2.8
6.4
8.8
9.7
9.8
6.45
2.4
9.8
9.6




$\begin{array}{lrrr}\text { IGM } & 70 & 9.6 & 18 \\ \text { IVL } & 55 & 5.9 & 12 \\ \text { JOR } & 55 & 4.5 & 14 \\ \text { KAJ } & 66 & 2.0 & 18 \\ \text { KLB } & 51 & 1.1 & 16 \\ \text { KLJ } & 49 & 6.9 & 14 \\ \text { KNA } & 59 & 1.9 & 16 \\ \text { KRK } & 33 & 5.3 & 14 \\ \text { LAA } & 67 & 15.5 & 14 \\ \text { LAJ } & 69 & 1.1 & 16 \\ \text { LAM } & 58 & 1.1 & 18 \\ \text { LAR } & 61 & 10.5 & 14 \\ \text { LIL } & 72 & 1.2 & 16 \\ \text { MCH } & 69 & 20.5 & 12 \\ \text { MOR } & 67 & 1.2 & 16 \\ \text { OLC } & 54 & 1.1 & 20 \\ \text { OLF } & 78 & 10.6 & 16 \\ \text { OSF } & 65 & 9.8 & 10 \\ \text { OWD } & 62 & 2.1 & 13 \\ \text { PEJ } & 52 & 6.3 & 13 \\ \text { POR } & 64 & 1.1 & 18 \\ \text { RAM } & 41 & 1.1 & 14 \\ \text { RER } & 79 & 7.9 & 12 \\ \text { ROW } & 49 & 4.4 & 14 \\ \text { SCJ } & 61 & 1.5 & 14 \\ \text { SHR } & 75 & 1.1 & 16 \\ \text { SIW } & 69 & 1.8 & 15 \\ \text { SKD } & 53 & 5 & 13 \\ \text { SKR } & 67 & 12.8 & 10 \\ \text { SNE } & 72 & 1.2 & 14 \\ \text { SOM } & 55 & 1.3 & 12 \\ \text { SWR } & 67 & 6.5 & 18 \\ \text { TAW } & 64 & 1.1 & 20 \\ \text { TEW } & 62 & 13.8 & 14 \\ \text { WAC } & 75 & 8.3 & 20\end{array}$

$\begin{array}{lc}\text { Conduction } & 77.1 \\ \text { Broca's } & 19.5 \\ \text { WNL } & 95.5 \\ \text { Wernicke's } & 49.1 \\ \text { Anomic } & 84.4 \\ \text { Conduction } & 73.5 \\ \text { Broca's } & 23.8 \\ \text { WNL } & 96 \\ \text { WNL } & 96.1 \\ \text { Global } & 10.7 \\ \text { WNL } & 95.3 \\ \text { Broca's } & 58 \\ \text { Conduction } & 59.3 \\ \text { Broca's } & 28.3 \\ \text { Anomic } & 77.5 \\ \text { WNL } & 100 \\ \text { Broca's } & 34.1 \\ \text { WNL } & 94.8 \\ \text { Broca's } & 36.4 \\ \text { Broca's } & 15.6 \\ \text { WNL } & 95.2 \\ \text { Broca's } & 16.6 \\ \text { Broca's } & 68.5 \\ \text { Broca's } & 61.8 \\ \text { WNL } & 96.2 \\ \text { Wernicke's } & 37.6 \\ \text { Conduction } & 74.7 \\ \text { Broca's } & 19.5 \\ \text { Broca's } & 44.3 \\ \text { WNL } & 98.6 \\ \text { Wernicke's } & 16.1 \\ \text { WNL } & 100 \\ \text { Wernicke's } & 63.7 \\ \text { Anomic } & 92.6 \\ \text { Unclassifiable } & 92 \\ & \end{array}$

9.35
4.75
9.45
6.85
8.6
8.45
6.1
9.5
9.95
3.05
9.45
7
9.65
7.85
8.45
10
7.15
9.6
7.1
5.2
10
7.9
9.65
8.6
10
3.6
8.65
6.75
7.05
10
1.95
10
6.65
9.1
10

6.6
0
9.8
4.6
9.2
6.4
0.4
10
9.8
2
8.6
6.6
2.9
1.8
7.3
10
1.7
9.4
1.7
0
8.8
0
5.4
5.3
9.8
1.8
5.8
0
3.9
10
0
10
5
9.4
9.8

\begin{tabular}{|c|c|}
\hline 8.6 & 42 \\
\hline 0 & 0 \\
\hline 9.5 & 51 \\
\hline 2.1 & 0 \\
\hline 7.4 & 40 \\
\hline 7.9 & 43 \\
\hline 1.4 & 0 \\
\hline 9.5 & 55 \\
\hline 9.3 & 48 \\
\hline 0.3 & 0 \\
\hline 9.6 & 46 \\
\hline 5.4 & 4 \\
\hline 5.1 & 13 \\
\hline 1.5 & 1 \\
\hline 8 & 48 \\
\hline 10 & 60 \\
\hline 3.2 & 3 \\
\hline 9.4 & 48 \\
\hline 3.4 & 2 \\
\hline 0.6 & 0 \\
\hline 8.8 & 56 \\
\hline 0.4 & 0 \\
\hline 7.2 & 46 \\
\hline 6 & 25 \\
\hline 9.3 & 59 \\
\hline 3.4 & 5 \\
\hline 7.9 & 25 \\
\hline 0 & 0 \\
\hline 4.2 & 10 \\
\hline 9.3 & 50 \\
\hline 0.1 & 0 \\
\hline 10 & 58 \\
\hline 5.2 & 38 \\
\hline 8.8 & 55 \\
\hline 9.2 & 55 \\
\hline
\end{tabular}


Table 1 (continued)

\begin{tabular}{|c|c|c|c|c|c|c|c|c|c|c|c|}
\hline Patient code & $\begin{array}{l}\text { Age at } \\
\text { testing }\end{array}$ & $\begin{array}{l}\text { Years } \\
\text { post } \\
\text { onset }\end{array}$ & Education & Gender & $\begin{array}{l}\text { WAB aphasia } \\
\text { type }\end{array}$ & $\begin{array}{l}\text { WAB AQ } \\
(\max =100)\end{array}$ & $\begin{array}{l}\text { WAB } \\
\text { Fluency } \\
(\max =10)\end{array}$ & $\begin{array}{l}\text { WAB Auditory } \\
\text { Comprehension } \\
(\max =10)\end{array}$ & $\begin{array}{l}\text { WAB } \\
\text { Repetition } \\
(\max =10)\end{array}$ & $\begin{array}{l}\text { WAB } \\
\text { Naming } \\
(\max =10)\end{array}$ & $\begin{array}{l}\text { BNT } \\
\text { Spontaneous } \\
\text { Correct } \\
(\max =60)\end{array}$ \\
\hline WOW & 65 & 1.1 & 5 & $\mathrm{~F}$ & Conduction & 72.5 & 8 & 8.25 & 4.9 & 7.1 & 17 \\
\hline YEF & 73 & 1.3 & 12 & M & Conduction & 67.2 & 8 & 8.8 & 5.2 & 3.6 & 10 \\
\hline Mean & 61.47 & 4.83 & 14.3 & - & - & 68.78 & 6.55 & 8.3 & 6.19 & 6.33 & 29.8 \\
\hline \multicolumn{12}{|c|}{ Right hemisphere-injured patients } \\
\hline ALC & 62 & 1.1 & 15 & M & WNL & 99 & 10 & 10 & 9.8 & 9.7 & 55 \\
\hline BRJ & 77 & 7.8 & 12 & M & WNL & 97 & 10 & 10 & 9.8 & 8.7 & 53 \\
\hline BUE & 76 & 10.1 & 12 & $\mathrm{~F}$ & WNL & 99 & 10 & 10 & 9.8 & 9.7 & 52 \\
\hline GAD & 47 & 7.7 & 14 & M & WNL & 97 & 9 & 10 & 9.7 & 9.8 & 50 \\
\hline KLM & 64 & 16 & 17 & M & WNL & 100 & 10 & 10 & 10 & 10 & 59 \\
\hline RAE & 56 & 2.9 & 15 & M & WNL & 99.7 & 10 & 9.85 & 10 & 10 & 55 \\
\hline RUR & 69 & 11 & 7 & M & WNL & 99 & 10 & 10 & 10 & 9.5 & 57 \\
\hline SMR & 49 & 3.7 & 12 & M & WNL & 99.4 & 10 & 10 & 10 & 9.7 & 58 \\
\hline Mean & 62.5 & 7.54 & 13 & - & - & 98.76 & 9.88 & 9.98 & 9.89 & 9.64 & 54.88 \\
\hline
\end{tabular}

a These patients' Auditory Comprehension subtest scores were too high to classify them with Broca's aphasia on the WAB.

WAB administered at 4 months post onset; later WAB not available.

${ }^{\mathrm{c}}$ This patient's scores on the Naming subtests were too high to classify him with Anomic aphasia on the WAB. 
Table 2

CYCLE-R subtests used for assessing sentence comprehension in aphasic patients

\begin{tabular}{|c|c|c|}
\hline Title $^{\mathrm{a}}$ & Number of pictures & Example \\
\hline Simple Declaratives (2) & 3 & 'The girl is sitting' \\
\hline Possession (3) & 3 & 'The clown has a balloon' \\
\hline Active Voice Word Order (4) & 4 & 'The girl is pushing the boy' \\
\hline Double Embedding I (4) & 4 & $\begin{array}{l}\text { 'The clown that is big has } \\
\text { the balloon that is red' }\end{array}$ \\
\hline $\begin{array}{l}\text { Passive Voice Word Order I (Agentless } \\
\text { Passive) (4) }\end{array}$ & 3 & 'The boy is being chased' \\
\hline $\begin{array}{l}\text { Passive Voice Word Order II (Agentive } \\
\text { Passive) (5) }\end{array}$ & 4 & $\begin{array}{l}\text { 'The boy is being chased by } \\
\text { the girl' }\end{array}$ \\
\hline Subject Relatives Ending in N-V (7) & 4 & $\begin{array}{l}\text { 'The boy who is pulling the } \\
\text { girl is mad' }\end{array}$ \\
\hline Object Clefting (8) & 4 & $\begin{array}{l}\text { 'It's the clown that the girl } \\
\text { chases' }\end{array}$ \\
\hline Object (O-S) Relative Clauses (8) & 4 & $\begin{array}{l}\text { 'The girl is chasing the clown } \\
\text { who is big' }\end{array}$ \\
\hline Negative Passive (9) & 3 & $\begin{array}{l}\text { 'The girl is not being led } \\
\text { by the boy' }\end{array}$ \\
\hline Object (O-O) Relatives with Relativized Object (9) & 4 & $\begin{array}{l}\text { 'The girl is kissing the boy } \\
\text { that the clown is hugging' }\end{array}$ \\
\hline
\end{tabular}

a The number in parentheses after the title indicates the age by which a sample of American English-speaking children, tested by the CYCLE authors, were able to comprehend these structures.

an array of three or four line drawings. These subtests all involved complete declarative sentences referring to a full state of affairs (referent(s) and predication), not single words, phrases or fragments. An analysis of the logic of the test sentences can be found in Appendix A. Participants' responses to each sentence were recorded on an answer sheet by the examiner administering the CYCLE-R. Each of the 11 subtests contained five sentences for a total of 55 sentences. Though the CYCLE instructs that a score of 4 or better $(80 \%)$ should be considered a passing score for each subtest, this information was used for reference purposes only and was not formally included in the data analysis.

\subsection{Lesion reconstructions}

CT and/or MRI scans were obtained on each patient at a minimum of five weeks post onset. In nearly all cases, 3-D MRI scans were also performed at the time of testing. Lesions were reconstructed onto 11 standard templates based on the atlas of DeArmond, Fusco, and Dewey (1976). All reconstructions were completed by a board-certified neurologist experienced with the templates but blind to the behavioral deficits of the patient. The reliability of these lesion reconstructions has been verified for other studies by a second neurologist reconstructing the same cases (e.g. Knight, Scabini, Woods, \& Clayworth, 1988) and the method itself has been used by many laboratories using various different templates (e.g. Adolphs, Damasio, Tranel, Cooper, \& Damasio, 2000; Kertesz, 1979; Naeser \& Hayward, 1978). To compensate for the individual variation in gyral patterns and any differences in imaging angles, reconstructions were done using 
subcortical structures as landmarks. Lesion reconstructions were then entered into a Macintosh computer via electronic bitpad with software developed at the VA Northern California Health Care System in Martinez, California (Frey, Woods, Knight, Scabini, \& Clayworth, 1987).

\subsection{VLSM}

Computerized lesion reconstructions and CYCLE-R test scores were entered into a VLSM analysis (Bates et al., 2003) in which the effects of lesions on performance could be evaluated. For each voxel on the 11 templates, VLSM automatically divided patients into two groups, based on the presence or absence of a lesion in that voxel. Each voxel was $0.5 \mathrm{~mm}$ in size and, because the lesions were digitized, either contained a lesion or was lesion-free; no voxel could contain a partial lesion. Only voxels yielding a pre-determined number of cases in each group were included in the analysis. $T$-tests were then performed at each eligible voxel with the CYCLE-R score as the dependent variable, and the resultant $t$-values plotted in a color figure. VLSM algorithms utilize Matlab software (The Mathworks, Natick, MA) and can be found online at http://www.crl.ucsd.edu/vlsm.

\section{Results}

\subsection{Preliminary behavioral analyses - percent correct scores for the major subject groups}

\subsubsection{Performance of aphasic versus non-aphasic patients and controls}

A preliminary analysis was conducted to assess the general pattern of performance of aphasic patients for the different sentence types compared to non-aphasic and control participants. Toward this aim, percent correct scores for each of the 11 CYCLE-R subtests were calculated for each group. Data from the $46 \mathrm{LH}$ patients who classified with aphasia were compared to those from each of the other non-aphasic groups (LH WNL patients, RH control patients, and normal controls). As can be seen in Fig. 1, normal controls, RH patients and LH WNL patients performed well on all subtests, compared to the LH aphasic patients. (Normal controls were administered only the last five subtests due to time constraints and the absence of errors in the earlier subtests during pilot testing.) LH aphasic patients, as a group, performed best on the Possession and Simple Declaratives subtests but showed a gradual decline in performance as the tasks involved more integration of grammatical information. Calculation of $95 \%$ confidence intervals $($ alpha $=0.05)$ around each subtest mean for each group revealed that LH aphasic patients performed significantly worse than each of the non-aphasic groups on the 11 subtests (see Fig. 1). The non-aphasic groups did not differ from each other. ${ }^{1}$ This analysis

\footnotetext{
${ }^{1}$ Although RH patients, as a group, significantly outscored LH aphasic patients, one RH patient (BRJ) performed poorly on Subject Relatives, Object (O-O) Relatives, and Negative Passives despite scoring WNL on the WAB. This patient was the only RH patient with a complete occlusion of the middle cerebral artery, resulting in a massive RH infarction.
} 


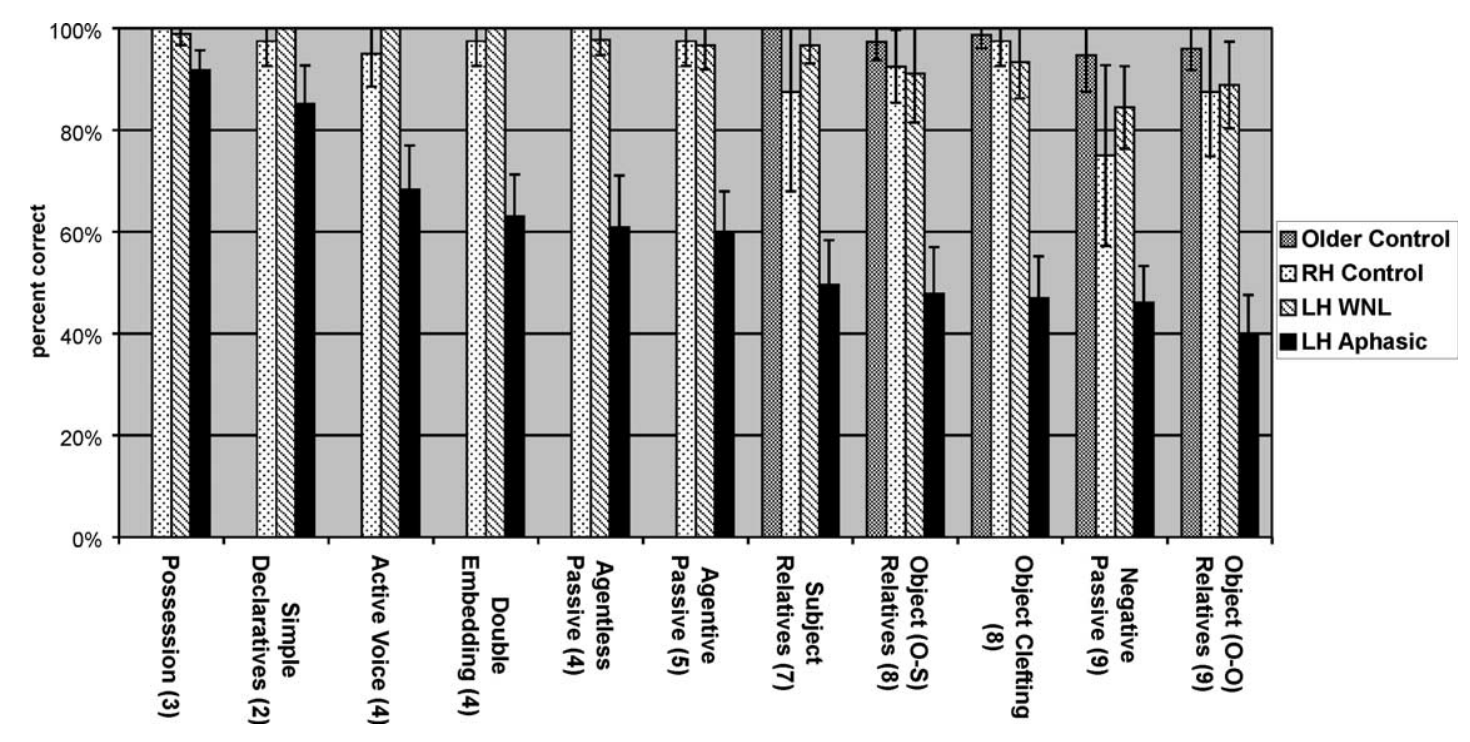

Fig. 1. Percent correct scores and 0.05 confidence intervals for aphasic and non-aphasic participants on each of the 11 CYCLE-R subtests. 
demonstrated that aphasic patients, as a group, exhibited difficulty on even the simplest of these tasks as compared to the control groups. The analysis also confirmed that the presence of a brain injury alone (as with the LH WNL and RH control patients) was not enough to affect performance on these tasks, as these patients did not differ from normal controls.

\subsubsection{Performance of patients with different aphasia types}

Since discussions of aphasia type feature heavily in the patient literature, a comparison of patterns of performance exhibited by patients with different aphasia types was first conducted. Average percent scores for each of the 11 CYCLE-R subtests were calculated for each aphasia type (see Fig. 2). Patients with Anomic aphasia exhibited the best performance, declining only on the more difficult linguistic comprehension tasks. Patients with Conduction aphasia and Broca's aphasia began to decline on the Active Voice subtest, achieving a score of less than $80 \%$ on this and subsequent tasks that relied more heavily on morphosyntax. It should be noted that there was a considerable range of performance in both groups, with some patients with Broca's and Conduction aphasia performing well on many of the more complex tasks. Patients with Wernicke's aphasia performed worst on all subtests, with their highest scores seen on the Possession subtest. The patient with Global aphasia (LAJ; not shown in the figure) also performed poorly on all subtests except for Possession. Three patients (not shown) whose aphasia type could not be classified performed relatively well, except for the last few subtests.

Ninety-five percent confidence intervals (alpha $=0.05$ ) around the means for each major group of aphasic patients can also be seen in Fig. 2. Patients with Wernicke's aphasia differed from each of the non-aphasic groups plotted in Fig. 1 on all subtests. Those patients with Broca's aphasia did not differ from any of the non-aphasic groups on Possession or Simple Declaratives but differed on Active Voice and subsequent sentence types. Conduction aphasic patients began to differ from all controls on Double Embedding and continued to decline, overlapping with RH controls only on Negative Passives. Anomic aphasic patients differed from all but the RH controls on Subject Relatives, from all controls on Object (O-S) Relatives and Object Clefting, and from all but the RH controls on Negative Passives and Object (O-O) Relatives.

\subsection{Lesion analysis of the brain areas related to sentence comprehension performance}

The primary goal of this study was to determine the relationship between lesions to specific areas of the brain and performance on this particular measure of sentence comprehension. To this end, a VLSM analysis (Bates et al., 2003) was performed on the data from all $64 \mathrm{LH}$ patients. Data were first analyzed using a composite score to gain an overview of the potential brain areas that might affect CYCLE-R performance. This analysis was followed by separate VLSM analyses of the individual CYCLE-R subtests to evaluate whether specific areas might differentially affect comprehension of the individual sentence types.

\subsubsection{VLSM of overall CYCLE performance}

In order to determine the lesioned areas that influenced overall CYCLE-R sentence comprehension performance, lesion reconstructions from all $64 \mathrm{LH}$ patients were entered 


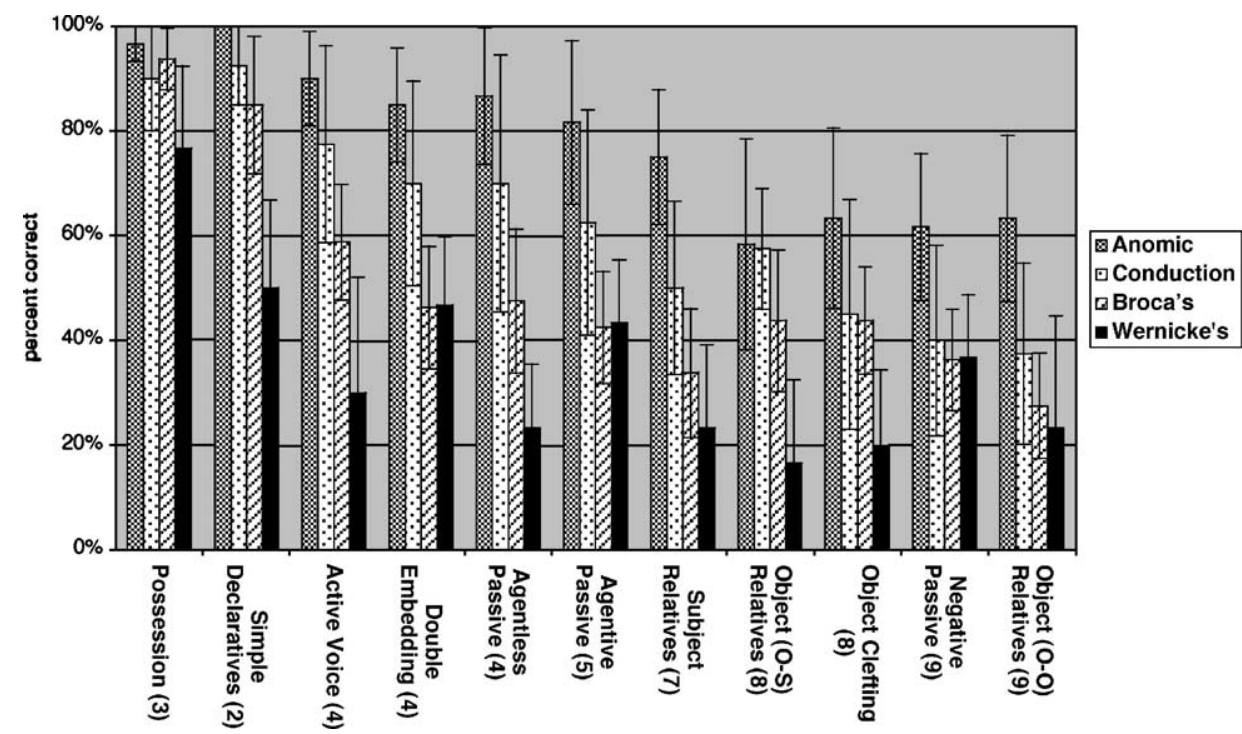

Fig. 2. Percent correct scores and 0.05 confidence intervals for patients with different aphasia types on each of the 11 CYCLE-R subtests. 
into the VLSM analysis along with a composite score that reflected the sum of all 11 CYCLE-R subtests. $T$-tests were performed at each voxel containing at least eight patients in each lesioned and non-lesioned group (to control for spurious results in peripheral voxels that might only contain a few patients). $T$-statistics were plotted on the reconstruction templates and can be seen in Fig. 3. T-values ranged from -1.4 to 6.3 (one-tailed), with those over 4.7 (depicted in orange through red) being statistically significant after Bonferroni correction that conservatively adjusted for the number of unique $t$-tests on all 11 slices. (The Bonferroni method typically divides the $P$-value by the total number of $t$-tests performed. However, due to their small size, neighboring voxels could contain lesions from the same patients and thus yield the same $t$-score and associated $P$-value. VLSM ignores these redundant $t$-tests and corrects by dividing the $P$-value by the number of unique $t$-tests performed.)

The analysis revealed that CYCLE-R performance was affected by lesions in five distinct left hemisphere regions. These included the middle temporal gyrus and underlying white matter (MTG; Slices 3-6), the anterior STG (ant BA22; Slices 1-5), the superior

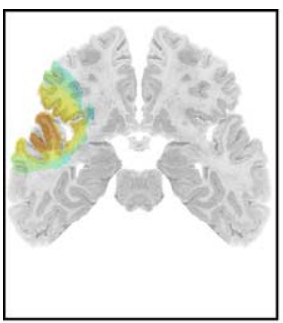

1

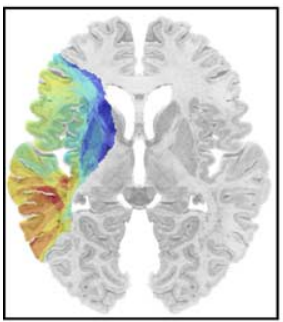

5

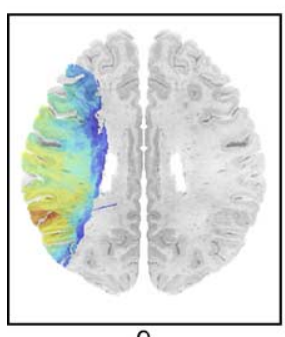

9

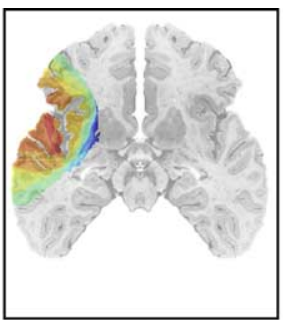

2

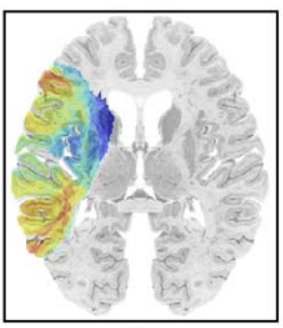

6

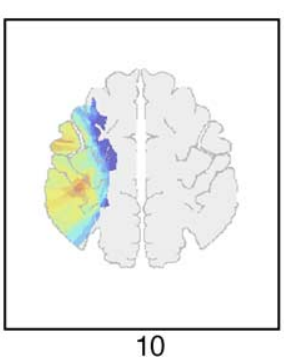

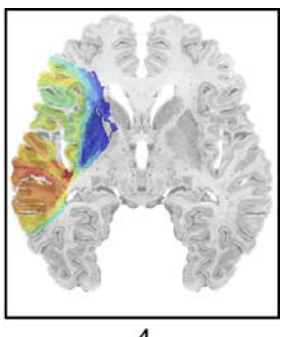

4
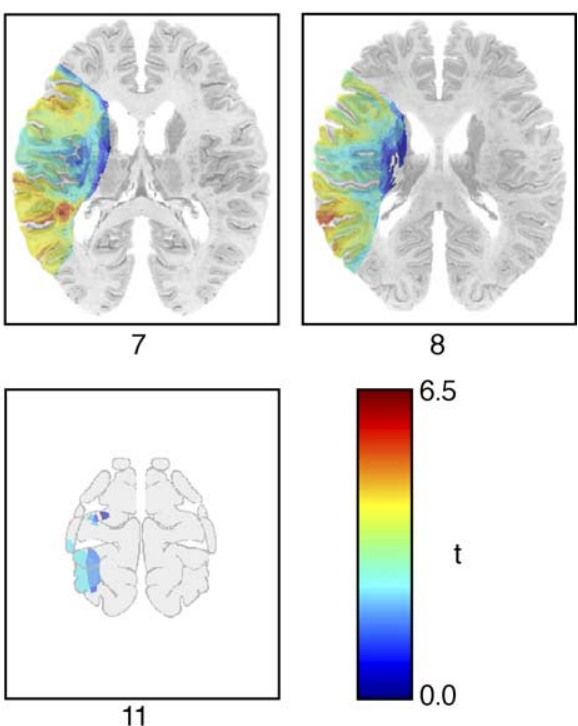

Fig. 3. VLSM plot of positive $t$-values obtained by comparing patients with and without lesions at each voxel on the CYCLE-R sentence comprehension measure. 


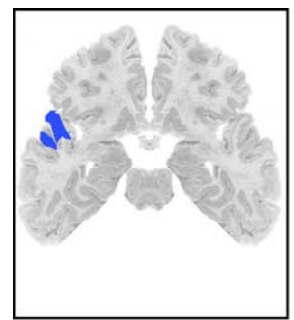

1

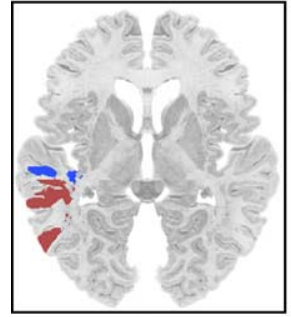

5

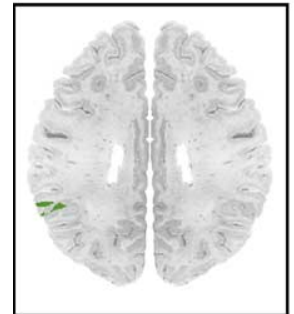

9

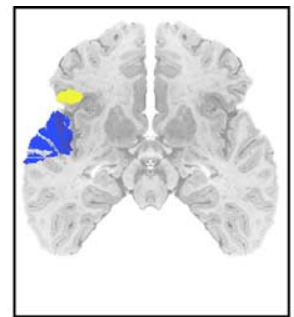

2

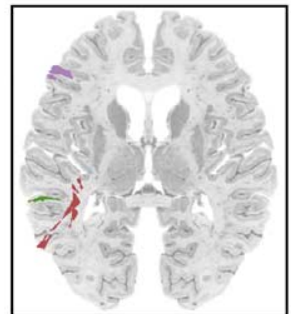

6

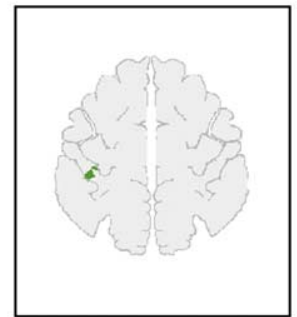

10

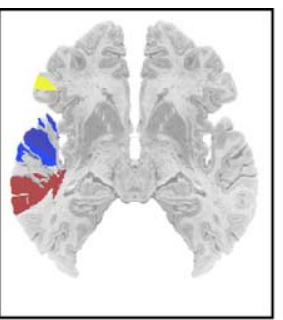

3

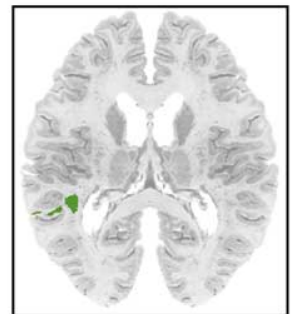

7

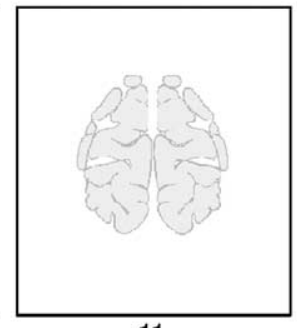

11

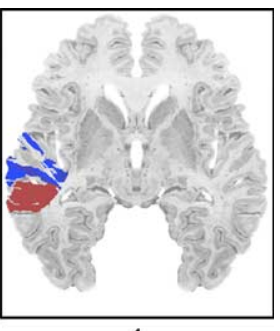

4

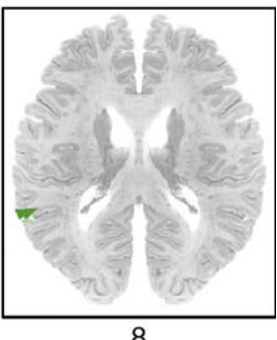

MTG

ANT BA22

STS/BA39

BA46

BA47

Fig. 4. Locations of four VLSM-defined areas found to contribute to different components of sentence comprehension.

temporal sulcus and angular gyrus (STS/BA39; Slices 6-10), ${ }^{2}$ mid-frontal cortex in Brodmann's area 46 (BA46; Slice 6), and Brodmann's area 47 of the inferior frontal gyrus (Slices 2-3). Lesions in Brodmann's areas 44 and 45 (Broca's area) were not seen to contribute, nor was the posterior portion of BA22 (Wernicke's area). The five significant areas were isolated and labeled for easier viewing and are depicted in Fig. 4. Summary statistics can be seen in Table 3 .

\subsubsection{VLSM analyses of individual CYCLE-R subtests}

Individual VLSM analyses were also performed on each of the CYCLE-R subtests. Lesion and behavioral data from all $64 \mathrm{LH}$ patients were entered into an analysis for each subtest. $T$-tests were again performed between lesioned and non-lesioned patients at each

\footnotetext{
${ }^{2}$ A region of significance was found deep in the white matter on Slice 7. Although it appears contiguous to the STS/BA39 lesion, it is possible that it represents a significant area of its own, perhaps important for the transmission of information to and from key temporal lobe regions. Until further investigations can be conducted, this region will be considered part of the STS/BA39.
} 
Table 3

Summary statistics for VLSM-defined areas

\begin{tabular}{lclll}
\hline Brain area & Slice & Approximate Talairach coordinates & $t$-value & Bonferroni-corrected $P$-value \\
\hline \multirow{2}{*}{ Middle temporal gyrus } & 3 & $-61.6,-23.0,-6.0$ & 4.90 & 0.028 \\
& 3 & $-60.7,-34.3,-6.0$ & 4.90 & 0.028 \\
& 4 & $-63.1,-29.2,-1.0$ & 4.90 & 0.028 \\
& 5 & $-60.2,-37.2,4.0$ & 4.96 & 0.022 \\
& 5 & $-52.7,-61.5,4.0$ & 4.86 & 0.032 \\
Anterior BA22 & 6 & $-55.1,-61.5,9.0$ & 5.22 & 0.008 \\
& 1 & $-51.3,13.0,-16.0$ & 4.81 & 0.038 \\
& 2 & $-48.5,11.5,-11.0$ & 5.62 & 0.002 \\
& 3 & $-54.6,2.0,-6.0$ & 5.65 & 0.002 \\
& 4 & $-57.4,1.0,-1.0$ & 4.92 & 0.026 \\
& 4 & $-64.9,-10.8,-1.0$ & 5.19 & 0.010 \\
BA47 & 4 & $-64.9,-19.4,-1.0$ & 4.89 & 0.028 \\
& 5 & $-53.2,-19.4,4.0$ & 4.81 & 0.039 \\
BA46 & 2 & $-46.6,22.6,-11.0$ & 5.03 & 0.017 \\
Posterior STS/BA39 & 3 & $-48.5,31.6,-6.0$ & 4.85 & 0.033 \\
& 6 & $-48.5,29.6,9.0$ & 4.74 & 0.049 \\
& 6 & $-48.9,36.6,9.0$ & 5.11 & 0.013 \\
& 7 & $-60.2,-41.7,14.0$ & 4.97 & 0.022 \\
& 8 & $-60.7,-39.4,19.0$ & 5.26 & 0.007 \\
& 9 & $-55.1,-42.3,34.0$ & 5.28 & 0.007 \\
& 10 & $-34.8,-18.0,49.0$ & 5.21 & 0.009 \\
& & & 4.77 & 0.044 \\
& & & &
\end{tabular}

Table 4

Summary of results for VLSM analyses of individual CYCLE-R subtests

\begin{tabular}{llllllll}
\hline Subtest & \multicolumn{7}{l}{ Areas and slices where significance was found } \\
\cline { 2 - 7 } & MTG & Ant. BA22 & STS/BA39 & BA46 & BA47 & Deep STG & Postcentral gyrus \\
\hline Possession & 3 & - & - & - & - & - & - \\
Simple Declaratives & $3-7$ & - & - & - & - & - & - \\
Active Voice & $3-6$ & Deep $2-3$ & $6-10$ & 6 & - & - & - \\
Double Embedding & Deep 3 & $1-5$ & - & 6 & $2-3$ & 7 & - \\
Agentless Passive & $3-6$ & $1-3$ & - & - & - & 7 & - \\
Agentive Passive & - & - & 10 & - & - & - & 9 \\
Object (O-S) Relatives & - & - & - & 6,7 & $2-3$ & - & - \\
Subject Relatives & - & $2-3$ & $8-9$ & 6 & $2-3$ & - & - \\
Object Clefting & - & $3-4$ & 10 & - & - & - & - \\
Negative Passives & - & - & 9 & - & - & - & - \\
Object (O-O) Relatives & - & - & $9-10$ & - & - & - & - \\
\end{tabular}

These findings are based on highly significant $t$-test results for each voxel, adjusted by Bonferroni correction for the number of unique regions tested. Individual VLSM maps for each subtest could not all be reproduced here, but are available upon request from the first author. 
voxel that had at least eight patients in each of the two groups. Brain maps were constructed based on these $t$-statistics, Bonferroni-corrected for the number of unique $t$-tests performed on all slices. The results are summarized in Table 4. Overall, the same five regions emerged as important areas for CYCLE-R performance as were found in the analysis of the composite score. However, certain areas were seen to support performance on some tasks more than others.

The MTG emerged early on with the subtests of Possession and Simple Declaratives. Patients whose lesions included this region performed worse on these subtests than patients without lesions there. MTG-lesioned patients also performed worse than nonMTG-lesioned patients on Active Voice, Double Embedding, and the Agentless Passive. On subsequent subtests, MTG patients still performed poorly as discussed above, but not significantly worse than other LH-injured patients. Thus, this region did not emerge as uniquely important for these tasks. The fact that these patients are showing significant deficits on all subtests implies a fundamental comprehension deficit, perhaps even at a level that affects word comprehension.

Anterior BA22 emerged on Active Voice, Double Embedding, and the Agentless Passive, and then again on Subject Relatives, and Object Clefting. These sentences differ from the earlier subtests of Possession and Simple Declaratives in that they now require the assignment of animate referents to distinct thematic roles and the identification and processing of more complex structures. It is possible that these patients may be having difficulty at the most basic levels of constituent-structure processing. We will return to this issue in Section 4.

Patients with lesions in the STS/BA39 regions were significantly different from those without that lesion on Active Voice, Agentive Passive, Subject Relatives, Object Clefting, Negative Passives, and Object (O-O) Relatives. This region, though not originally hypothesized, is clearly playing a role in language comprehension. Its potential role will also be discussed in Section 4.

BA46 emerged as a significant region for Active Voice, Double Embedding, Object (O-S) Relatives, and Subject Relatives. Nearby area, BA47, also emerged on Double Embedding, Object (O-S) Relatives, and Subject Relatives. Possibly, these areas contribute in similar ways since both significantly affected performance on virtually the same subtests. These shared types all involve relative clauses and so require the mapping of a noun phrase referent to a role in the main clause as well as a role in the embedded clause. Though neighboring on these two areas, Broca's area (BA 44 and 45) did not emerge as important for performance on any of these CYCLE-R subtests.

The lateral cortex in the posterior part of Brodmann's area 22, typically thought of as Wernicke's area, was not found to be significant at any time. A small white matter region underlying the posterior STG and MTG was found to be significant on Double Embedding and Agentless Passive and also appeared on the composite analysis as a contiguous area to the STS/BA39 region. Though this region is not in the cortical zone attributed to Wernicke's area, it is true that white matter lesions can significantly disrupt behavior by causing disconnections between many cortical regions of the brain, including the posterior STG and other cortical areas.

The postcentral gyrus (BA 1, 2, 3) was found to be significant on Slice 9 for the Agentless Passive. This is possibly a spurious finding, since it is the only time 
the postcentral gyrus emerges in these individual analyses and was not found in the overall analysis of the composite score. Though its role may be significant and should not be completely dismissed, further exploration with more appropriate measures is necessary before including it in further discussions.

\subsubsection{Performance of patients with lesions involving the individual VLSM-determined regions versus patients whose lesions spared these areas}

As another means of exploring the effects of lesions to these VLSM-determined regions, performance of patients with lesions involving these areas (or associated networks) was compared to that of patients whose lesions spared these same regions. Posthoc analyses were conducted comparing these groups on their performance on each individual CYCLE-R subtest. Patients were first coded for the presence or absence of a lesion in each of the five VLSM-defined areas. Only those patients whose lesions involved the bulk of a given region as depicted in Fig. 4 were considered "lesioned". Mean percent correct scores resulting from lesions to each of these regions were then calculated for each subtest. These are graphed in Fig. 5 and reflect average performance from any patient with a lesion involving the bulk of that area. Note that many patients' lesions involved multiple regions and thus these scores are not independent of one another and cannot be compared to each other, only to those of the patients with lesions sparing these areas. This issue of interdependent areas will be discussed in Section 4.

Examination of Fig. 5 reveals that patients whose lesions involved the MTG performed well on Possession, but performed poorly (below 50\%) for the remaining tests. Those whose lesions involved any of the other four regions performed at passing levels for Possession and Simple Declaratives, but failed on more complex measures. Patients whose lesions spared all of the VLSM-defined areas are also plotted in Fig. 5. It can be seen that their lesions barely affected performance on these subtests, though minor deficits (similar to controls and still within passing range per CYCLE criteria) were seen on the last four subtests. Calculation of $95 \%$ confidence intervals $($ alpha $=0.05$ ) for these groups confirmed these impressions. Patients with lesions in any of the VLSM-defined areas differed from the group whose lesions spared these areas on all subtests except Possession. Thus, it appears that VLSM was successful in isolating areas critical for CYCLE-R performance since patients whose lesions spared these five areas performed very well.

On the Possession subtest, only the MTG group differed significantly from the group whose lesions spared all VLSM-defined areas. As stated above, all groups differed from the spared group on subsequent subtests, though the MTG group had the worst overall performance. These results indicated that MTG lesions appeared to have affected CYCLE-R performance more than the other areas on the simplest subtests, though all groups began to decline as the tasks increased in difficulty.

\subsubsection{Post-hoc analyses of word-level comprehension data}

The preceding analyses suggest a deficit at early stages of language comprehension for patients with lesions involving the MTG. This deficit likely reflects a problem that affects word-level processing. For this reason, a closer look was taken at other data obtained on the same patients, in particular, the three Auditory Comprehension subtests of the WAB summarized in Table 1. These subtests included Yes/No questions requiring the patient to 


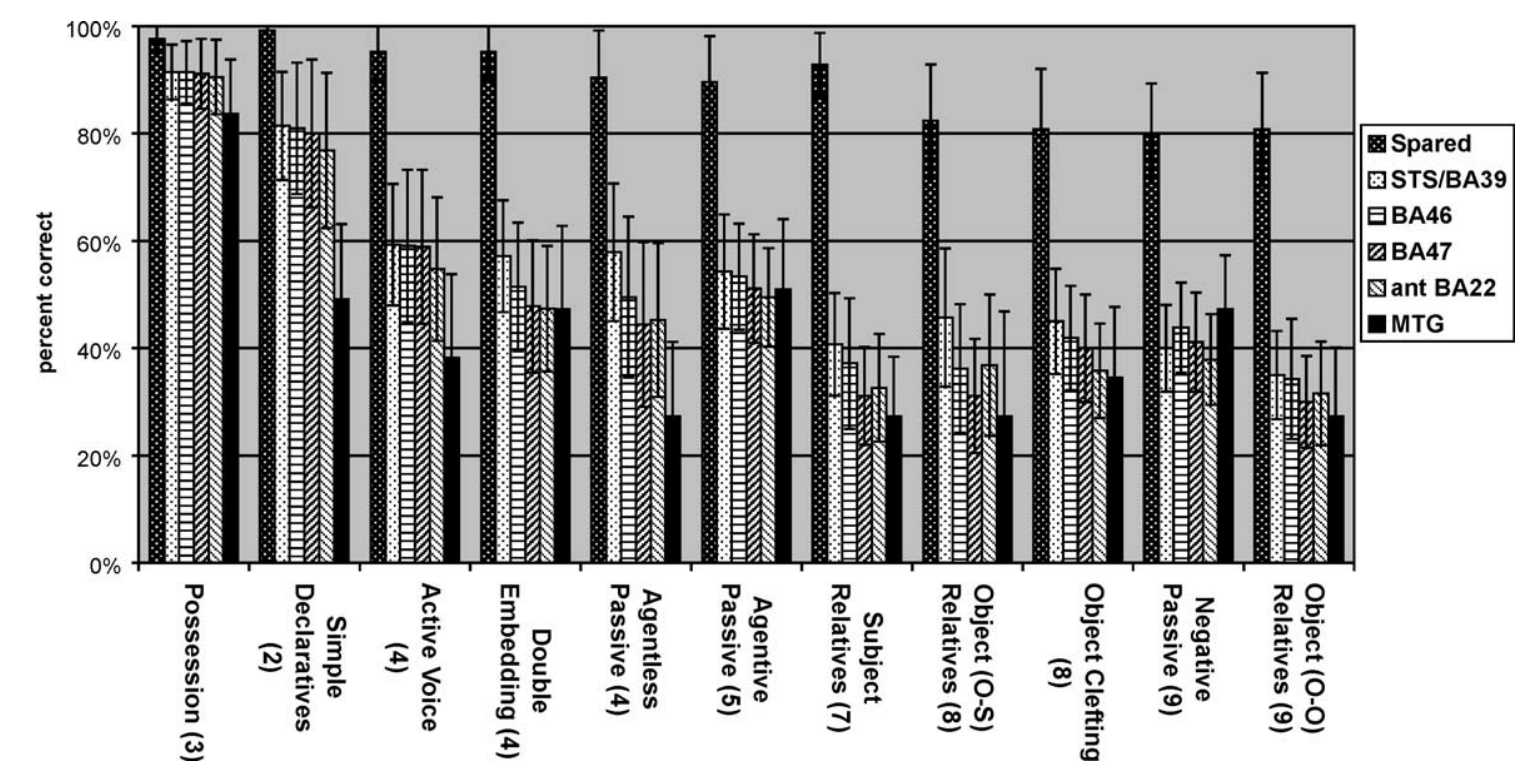

Fig. 5. Percent correct scores and 0.05 confidence intervals for patients whose lesions either spared or encompassed VLSM-defined areas. 
listen to a question and merely respond with a 'yes' or a 'no'; Single Word Comprehension in which patients hear a word and point to the corresponding picture, object, or body part; and Sequential Commands requiring actions in response to commands that increase in the number and complexity of steps needed to perform the action sequence. $T$-tests were conducted on each of these WAB comprehension subtests by comparing patients with MTG lesions $(n=12)$ to those whose lesions included a VLSM-defined area but spared the MTG and therefore also had confirmed comprehension deficits $(n=27)$. Patients with MTG lesions performed significantly worse than patients whose lesions spared the same area on Single Word Comprehension, confirming a deficit at or below the word level in this group (mean $\mathrm{MTG}=32.09$, mean non-MTG $=51.28, t=4.41$, $P<0.0001)$. As expected, they also differed significantly at the sentential level on Sequential Commands (mean $\mathrm{MTG}=38.45$, mean non-MTG $=62.0, \quad t=3.76$, $P=0.0006$ ) and Yes/No questions (mean $\mathrm{MTG}=47.18$, mean non-MTG $=55.68$, $t=2.59, P=0.014)$.

These results confirmed a significant deficit in the comprehension of words in the MTG-lesioned group. To assess how generalized this deficit was, MTG patients $(n=12)$ were also compared to patients with lesions in the other VLSM-defined areas $(n=27)$ on their composite WAB Naming subtest score $(\max =10)$ and their score on items spontaneously named for the Boston Naming Test (BNT; max =60). MTG patients performed significantly worse on WAB Naming than patients whose lesions were not in the MTG but in other VLSM-defined areas (mean MTG $=2.65$, mean non-MTG $=5.98$, $t=3.27, P=0.002)$. These patients were also seen to perform significantly worse on the $\mathrm{BNT}$ (mean $\mathrm{MTG}=7.75$, mean non-MTG $=24.59, t=2.8, P=0.008$ ). Thus, within the 39 patients showing comprehension deficits on the CYCLE-R, a clear subgroup of MTGlesioned patients emerged as having the most severe problems, apparently affecting the word level for both comprehension and production in these patients.

\section{Discussion}

VLSM yielded several distinct areas within the left hemisphere that appeared to affect language comprehension as measured by the CYCLE-R tasks. These regions included (a) the posterior MTG and underlying white matter, (b) the anterior STG (anterior BA22), (c) the superior temporal sulcus and angular gyrus (STS/BA39), and (d) two frontal areas including Brodmann's areas 46 and 47. Patients with lesions sparing these areas performed comparably to RH-lesioned patients and normal controls on each of the CYCLE-R subtests. Lesions to Broca's and Wernicke's areas were not elicited as key areas for these particular tasks.

Patients with lesions involving the MTG were seen to have the worst overall scores and differed from all control groups on all subtests. These patients also demonstrated deficits on the word-level comprehension and naming tests of the WAB and the BNT. Such poor performance suggests a deficit in processing at the word level or with mechanisms that help to support word-level processing. On the other hand, patients with lesions encompassing anterior BA22, the STS/BA39 region, or the two frontal Brodmann's areas 46 and 47 had difficulty on tasks that involved utterance processing above the level 
of the word. They all had difficulty on CYCLE-R subtests that required attention to grammatical structures in order to correctly interpret the sentence (i.e. the relevant subtests could not be passed by relying on lexical content only). This dissociation between word- and sentence-level processing will be discussed further below.

One of the questions we set out to explore was whether lesion studies and those from functional imaging could be better synthesized in the effort to map language areas in the brain. Though lesion studies certainly gave us our foundation in this endeavor, functional imaging studies have explored other regions more expeditiously, particularly once the technique no longer had to rely on regions of interest defined by earlier lesion studies. PET and fMRI studies are now finding that frontal and temporal regions other than Broca's and Wernicke's areas might also play a role in language comprehension, as do parietal regions. While some lesion studies have also been successful at identifying additional regions that play a role in language processing, large-scale studies involving adequate numbers of patients have been rare (e.g. Caplan, Hildebrandt, \& Makris, 1996).

The present study used VLSM with 64 well-characterized left hemisphere stroke patients to explore brain regions that, when lesioned, disrupted performance on a language comprehension task. Our findings, through lesion analysis, were consistent with those from other investigators using lesion analysis or functional imaging. For instance, we, too, found that dorsolateral frontal areas (specifically BA46 and BA47) were important for the comprehension of sentences, as well as parietal area BA39, the angular gyrus. In addition, anterior BA22 re-emerged as an important region for the successful comprehension of CYCLE-R sentences. The MTG region was found to be important for supporting wordlevel processing that necessarily must occur before sentence comprehension can be achieved.

One caveat to any study that attempts to map cognitive functions is that brain regions cannot easily be separated from each other. In lesion analysis, injuries to the brain generally cause damage to multiple regions, and thus, patients with narrowly circumscribed lesions in only one key brain area are not often encountered. Furthermore, lesion studies may suffer from the possibility of diaschitic effects such that injuries to one area can cause dysfunction in remote, non-lesioned areas. These concerns are particularly valid in studies with small sample sizes, where patients' lesions may not be well distributed across the brain. The present study was able to achieve a notable sample size of 64 patients with lesions spanning across the peri-Sylvian region of the left hemisphere. Some patients' lesions were quite focal while a few resulted from total middle cerebral artery occlusions. Some involved only frontal regions, some only temporal or parietal. The greater the number of patients that can be included, the greater the number of combinations of lesioned areas, allowing a statistical analysis such as the one employed here to lessen the effects of any one grouping. Such large numbers are, admittedly, difficult to accumulate, but when achieved, offer an important balance to functional imaging studies.

The fact that Broca's and Wernicke's areas did not emerge as critical areas is another interesting point for discussion. Most of the patients in this study had lesions involving one or other of these two areas, and yet these regions were not found to contribute significantly to this measure of language comprehension. It should be noted that the areas that did emerge are adjacent ones, such that anterior BA22, BA46 and BA47 all surround Broca's 
area, and the MTG and angular gyrus both border on Wernicke's area. The robustness of these effects found for the surrounding areas and the size of these regions found to be significant make it unlikely that these findings are artifactual. Furthermore, recent work has shown that lesions to Broca's and Wernicke's areas do not lead to persisting Broca's or Wernicke's aphasia as once thought (see Dronkers, Redfern, \& Knight, 2000; Mohr, 1976 for reviews). Functional imaging has also reported a lack of activations in these areas, particularly if complex articulation or complex phonological perception are not involved (see Cabeza \& Nyberg, 2000). Thus, it is more likely that the classical findings of Broca's or Wernicke's area involvement is actually epiphenomenal and in fact due to the involvement of the distinct surrounding areas now being identified in two converging literatures.

Thus, we see that two groups of findings, each from very different sources, using different kinds of subjects and different measurement tools, have converged on a fundamentally important finding, that the complicated process of understanding language relies on many different brain areas distributed across the left peri-Sylvian region. The specific function each area might offer is the next question to be explored and one which can be guided by both functional imaging and lesion-based research.

\subsection{Possible contributions of the different areas}

What follows is a set of hypotheses concerning the potential contributions of each area to language comprehension. Our experience in working with aphasic patients, coupled with findings from this study and others in the literature, have led us to certain speculations regarding the possible roles these areas might each play in language comprehension. We outline these here as hypotheses we will test in future research and hope that investigators doing functional imaging might also find them interesting to pursue.

Each of the VLSM-defined areas will be presented in turn. Briefly, we suggest that the MTG and underlying white matter are involved in word-level comprehension, at the basic level of tying concepts to words. The anterior portion of Brodmann's area 22 may be critical for the comprehension of simple sentences or sub-sentential constituent structures, those that do not go beyond basic morphosyntactic structure. The frontal areas identified here may relate to working memory functions that assist in the comprehension of sentences that require manipulating components of complex sentence structures. Finally, the role of the angular gyrus region may have more to do with its relationship to auditory short-term verbal memory and the necessity to depend on this function during a sentence comprehension task that relies heavily on auditory rehearsal. Though the results of the present study did not drive all of these hypotheses, the findings are consistent with our suggestions and can serve as a guide to future research.

\subsubsection{The MTG and word-level comprehension}

The MTG area under discussion involves the posterior part of Brodmann's area 21 and the superior portion of BA37. Underlying white matter is also critically involved. As seen above, patients with primarily MTG lesions performed well on Possession, but failed all other subtests. Their performance was typically below all other groups and they consistently differed from both RH and normal controls and patients whose lesions spared 
VLSM-defined areas. This group consisted of the most severely aphasic patients overall, with a mean WAB AQ score of 38.08 (out of 100). Most of them classified with a severe Wernicke's, severe Broca's, or Global aphasia.

It is interesting to note that the Possession subtest that is easiest for the MTG group is fully stative, has a non-complex form of the verb, and could, in fact, be passed by comprehending only the high-frequency nouns in the sentence. The other subtests, all failed by the MTG group, involved the need to identify the meaning of the verb, and to recognize the role each participant played in that action. Thus, it seems probable that this group of patients might have difficulty at or below the most basic level of language comprehension, at the level of the word. These patients' poor performance on the single word comprehension subtest of the WAB, as well as their poor naming scores on the BNT, would support the hypothesis that the ties between concepts and their corresponding lexical representations have been affected in this group of patients.

Other lesion studies also support the possible involvement of the MTG in basic wordlevel processing. Patients with the most obvious and severe deficits in word processing are the severe and persisting Wernicke's aphasics with deep, large posterior temporal lobe lesions (Dronkers, Redfern, \& Ludy, 1995; Hart \& Gordon, 1990; Kertesz, 1979) or those with Global or severe Broca's aphasia, whose large fronto-temporo-parietal lesions also encompass this area. These patients have difficulty in any task that involves either naming objects or pictures, selecting objects or pictures that match printed or auditorily-presented words, or matching words that are semantically associated with other words or pictures. Patients with particularly severe and persisting deficits pertaining to word representation perform very poorly on confrontation naming tasks (naming objects or pictures) and are frequently unable to choose the correct name when given two or three choices. Indeed, the patients in the present study with MTG lesions met this behavioral profile, regardless of their aphasia type.

PET studies and current fMRI work also implicate the posterior mid-temporal lobe in tasks designed to elicit lexical processes (e.g. Binder et al., 1997; Damasio, Grabowski, Tranel, Hichwa, \& Damasio, 1996; Warburton et al., 1996; Wise et al., 1991). In a large survey of functional imaging studies, Cabeza and Nyberg (2000) cited numerous reports of activation in BA21 during various word recognition tasks. These included word listening (Binder et al., 1996), spoken word recognition (Howard et al., 1992), and listening to sentences (Schlosser et al., 1998), as examples. Indefrey and Levelt (2000) in their review of available studies on word production also identify the left posterior superior and middle temporal gyri as important sites for accessing word codes. Kaan and Swaab (2002) agree that the left middle temporal lobe has consistently been implicated in single word processing. Though other studies are somewhat varied in their precise findings, most show posterior middle temporal lobe involvement. For example, Cappa, Perani, Schnur, Tettamanti, and Fazio (1998) found that lexical-semantic decisions about animal names activated temporo-parietal cortex. Pugh et al. (1996) reported activation in primarily middle and superior temporal sites when participants made semantic category judgments.

These findings all provide evidence that the posterior temporal lobe is needed for wordlevel comprehension. Whether it is specifically the conceptual-semantic side, the phonological form side, or the actual linking between form and concept is unclear. The reason our patients succeed on the Possession subtest might be explained by the fact that 
they need only process high-frequency nouns that could be accessed from the right hemisphere.

\subsubsection{Anterior Brodmann's area 22 and the comprehension of simple sentences}

This region falls within the most anterior portion of Brodmann's area 22, anterior to primary auditory cortex, in the left anterior STG. It lies at least $6 \mathrm{~cm}$ from the temporal pole and thus is not resected in those patients undergoing left anterior temporal lobectomy. Patients with lesions encompassing the anterior BA22 region differed from those patients whose lesions spared all the VLSM-defined areas, as well as from RH and normal controls, on all subtests except Possession. Their performance on Simple Declaratives was close to the controls, but differed due to ceiling effects in the control groups. Most of these patients classified with a Broca's aphasia.

The Possession and Simple Declaratives subtests involved the most unmarked type of sentence structure, namely, simple intransitive, positive active declaratives with basic noun phrases consisting only of a determiner and a noun. In these sentences, there is no ambiguity of role assignment. The remaining sentences, failed by these patients, all required the identification of more complex semantic and morphosyntactic structures (e.g. reversible transitive sentences, passive morphology, embedding, etc.).

In the earlier presentations of this work referred to in Section 1, we presented evidence to suggest that the anterior portion of Brodmann's area 22 was involved in morphosyntactic processing (Dronkers et al., 1994a,b, 1996; see also Hagoort, Brown, $\&$ Osterhout, 2000). The importance of anterior portions of temporal cortex in morphosyntactic processing has begun to find more support in the literature. A few have even made specific reference to anterior BA22. For example, Hagoort et al. (2000) conducted a review of neurocognitive studies of sentence processing, including the working paper by Dronkers et al. (1996). They concluded that temporal cortex, including anterior portions of the STG, appears to be involved in morphosyntactic processing. Friederici and von Cramon (2000) argue that PET studies of sentence comprehension (e.g. versus word list reading) show that activation in the anterior temporal lobe does not vary with syntactic complexity, "but as a function of the presence of syntactic structure, per se" (p. 32). Their observation that this area has a very basic role in syntactic processing, rather than a more specific role in the processing of complex structures, is consistent with our current position.

Certain functional neuroimaging studies have found results directly pertinent to anterior BA22. In a PET study with normal subjects, Mazoyer et al. (1993) presented 16 right-handed young adult male French monolingual subjects with auditory linguistic input of various levels of complexity. The anterior temporal poles, including anterior BA22, were found to be activated in all the conditions that contained syntax. In another important PET study of syntactic comprehension, Stromswold, Caplan, Alpert, and Rauch (1996) asked English-speaking subjects to judge the acceptability of English utterances containing various sentence constructions. In one finding, the detection of nonsense words was subtracted from judgments of center-embedded sentences, thus comparing the condition with the greatest demand for syntactic processing to the condition with the most minimal demand. The areas of increased cerebral blood flow in this comparison included anterior BA22. Finally, Stowe et al. (1998) compared sentence- and word-processing in an 
fMRI study and found increased activation in anterior Brodmann's areas 21 and 22 for sentences when compared to word conditions. These authors conclude that "clearly, the anterior temporal lobe is involved more in the processing of sentences than of word lists."

Functional imaging and lesion analysis studies together suggest that very basic morphosyntactic aspects of sentence comprehension rely on left anterior temporal lobe structures, particularly anterior BA22. Its role in our developing model of language comprehension may be as simple as identifying base grammatical structures either through the identification of morphological cues (e.g. closed class items) or word order information. Meyer and colleagues note that the left anterior superior temporal region plays a role in processing constituent structures (Meyer, Alter, Friederici, Lohmann, \& von Cramon, 2002). Whether anterior BA22 is sensitive strictly to sentential or sub-sentential structures remains to be explored.

\subsubsection{STS/angular gyrus and auditory short-term verbal memory}

This region involves the STS and the angular gyrus (Brodmann's area 39). In our experience, patients with lesions involving this region show marked deficits on repetition tasks, particularly for longer sentences containing low-frequency words (e.g. "The pastry cook was elated") (Dronkers, Redfern, Ludy, \& Baldo, 1998). When asked to repeat such sentences, these patients reported that they could not recall the exact wording but could easily paraphrase parts or all of the sentence (e.g. "The baker was happy"). They would ask for longer sentences to be modeled several times and even then could not repeat them verbatim. Having lost this ability to retain traces in auditory short-term memory, patients were also poor at comparing two words to see if they rhymed, particularly if they were orthographically different (e.g. 'moose' and 'juice'). Repetition of single words and sentences with high-frequency words (e.g. "The telephone is ringing") did not typically present a problem for this group. Our patients with Conduction aphasia are characterized well by this behavior, though patients with other aphasia types can also exhibit a similar pattern of repetition errors if their lesions encompass the same area.

This deficit is consistent with the auditory short-term memory process that has been referred to as the "phonological loop", comprised of two sub-systems, the phonological store and the articulatory rehearsal system (Baddeley, 1986). The phonological store retains auditory information in a sound-based code that can be accessed through articulatory rehearsal. Patients with left parietal lesions have been noted to have deficits in auditory short-term memory (Saffran \& Marin, 1975; Warrington \& Shallice, 1969) and functional imaging studies have implicated the same area in tasks accessing the phonological store (see Cabeza \& Nyberg, 2000; Jonides et al., 1998). Baldo and Dronkers (1999) compared frontal lobe patients to parietal patients on various tasks of working memory and found parietal patients to have difficulty with those tasks requiring access to the phonological store while those with frontal lesions did not. Hickok and Poeppel (this issue) also believe that the phonological store is based in the left inferior parietal lobe and is part of an auditory-motor interface that ties auditory representations of speech with articulatory representations in the frontal cortex.

These findings together suggest that the STS/BA39 lesions of the patients studied here may have influenced their performance on this sentence comprehension task because of the auditory short-term memory deficit. Indeed, all but one of our Conduction aphasics fell 
into this group and the remaining patients with STS/BA39 damage certainly had compromised repetition scores on the WAB. It is likely that this deficit affected how well these patients could rehearse the sentence while comparing it to each picture in the array. Thus, this area may contribute to language comprehension only when the task requires the participation of auditory rehearsal. The data here do not confirm this hypothesis, but they are certainly consistent with it.

\subsubsection{Left frontal cortex and the manipulation of the computed components of complex structures}

The left frontal lobe has perhaps received the most attention in terms of its potential role in speech and language functioning. The most celebrated frontal region has, of course, been Broca's area. Although Broca himself thought the area only supported articulatory functions (Broca, 1864), Broca's area has been highly associated with sentence comprehension since the 1970s. At that time, patients with Broca's aphasia, who were generally thought to understand language, were noted to have comprehension deficits for more complex grammatical structures (Zurif et al., 1972). Since patients with Broca's aphasia were believed to have lesions in or around Broca's area, it was assumed that Broca's area played a key role in syntactic processing.

It is now recognized that the relationship between Broca's area and Broca's aphasia is not as consistent as once thought (Kaan \& Swaab, 2002; Mohr, 1976; Mohr et al., 1978). Lesions to Broca's area alone do not result in a Broca's aphasia, nor do Broca's aphasic patients necessarily have lesions in Broca's area (Dronkers, Shapiro, Redfern, \& Knight, 1992). In fact, lesions to Broca's area alone are known to produce only a transient mutism that resolves within 3-6 weeks. This finding suggests that Broca's area may be involved in some aspect of articulation, but does not address its role in sentence comprehension. Still, Broca's area frequently emerges in functional imaging studies of sentence processing (e.g. Just, Carpenter, Keller, Eddy, \& Thulborn, 1996). However, it also becomes activated in word-level tasks (e.g. Friedman et al., 1998). This suggests that Broca's area is not dedicated to sentence processing but supports a function common to both. In fact, Broca's area can show activation in such non-linguistic tasks as imagery of motion (Binkofski et al., 2000). Considering the hypothesis that Broca's area may be most involved in articulation, its activation in all of these tasks may be due to subjects' covert articulation while formulating a response.

Despite this caveat, a consensus seems to be forming that whatever role Broca's area may play, it may relate to known working memory functions of the frontal areas. (It should be noted that there is a wide distribution of Talairach coordinates (Talairach \& Tournoux, 1988) reported in the functional imaging literature that are referred to as part of Broca's area.) The processing of a passive voice sentence, for example, may require working memory to assist in the temporary retention of information while other relevant parts of the sentence are being manipulated (i.e. to resolve the assignment of thematic roles to arguments). Miyake, Carpenter, and Just (1994) have proposed that sentence processing relies on such general verbal working memory mechanisms while Caplan and Waters (1999) consider Broca's area to be involved in working memory specifically for syntactic processing. Friederici (2002) breaks Broca's area into its component regions and suggests that Brodmann's area 44 is involved in working memory for both phonological 
and syntactic structure. This area becomes active first for phonology and later for syntax as the time course for the comprehension process unfolds. Brodmann's area 45 together with Brodmann's area 47 is viewed as being specifically involved in working memory for semantic features and thematic structure where processes of syntactic reanalysis and repair are required. These areas come online after Brodmann's area 44 has finished its processing role and where comprehension of complex sentences must rely on general memory resources.

All of these theories indicate a move towards a view that syntactic comprehension problems arise from a computational rather than a conceptual deficit. Newer theories are taking a more dynamic view of how the brain integrates different linguistic and cognitive components and are examining the time course of these operations.

The frontal areas identified in the VLSM analysis included Brodmann's areas 46 and 47. As Friederici's analysis already indicates, larger areas besides just Broca's area may be required for the processing of more complex sentences. In fact, neurocognitive studies have already implicated frontal areas adjacent to Broca's area as important for working memory in non-linguistic as well as linguistic tasks (e.g. D'Esposito, Postle, Ballard, \& Lease, 1999; Petrides, 1994). Cabeza and Nyberg's (2000) analysis of imaging studies of working memory supports the view that BA45/47 is recruited for selecting or comparing information, while BA9/46 might be more involved in the manipulation of information in working memory. Since large lesions are typically required to produce a Broca's aphasia, it is likely that these regions may also become compromised in some patients and may contribute to their comprehension deficits for complex morphosyntactic structures. Clearly, lesion studies must take into account new data both from general neurocognitive studies and neuroimaging studies of language in order to resolve this problem.

\subsection{Conclusion}

We set out to investigate if a new method of lesion analysis with a substantial number of patients performing a language comprehension task would reveal similar brain areas to those reported in the functional imaging literature. A VLSM analysis with 64 LH stroke patients revealed the participation of five brain areas also implicated in previous lesion and functional imaging studies. This result is, in itself, most heartening and confirms the possibility of convergence between these different approaches.

The areas identified by VLSM analysis in conjunction with those seen to be involved in functional imaging provide support for the claims made by Caplan (1992) and others that language comprehension involves the entire peri-Sylvian region of the left hemisphere. However, the convergence of the two literatures also shows that this complex process might be broken down into functional components that future work can begin to tease out in more detail. Our own plan for further study is to investigate the specific deficits exhibited by patients with MTG lesions and to examine more carefully the nature of their word-level comprehension problem. We are also examining the deficits we believe relate to anterior BA22 lesions that might be causing problems with sentences that require identification of basic morphosyntactic structures. Other work with both patients and fMRI is investigating how frontal involvement might affect constructions requiring maintenance and manipulation of syntactic and/or semantic information, and further patient work is also examining the role of the inferior parietal lobule and STS/STG in auditory short-term verbal memory. 
The fact that both lesion and functional imaging work are not finding the classic Broca's and Wernicke's areas to be as important as neighboring areas in language comprehension suggests a further avenue of future research. Now that other areas have begun to feed into the mix, the specific roles these areas might actually play will be an important issue to explore. Our own interests are currently driving us to examine whether these areas might be specific to input and output mechanisms for language, and also to strive for a better definition of the cortical boundaries of these two classic areas.

Other issues we think are important to consider in future research concern the interdependence of specific brain regions within the large lesion that typically produces a persisting severe aphasia. For example, most of our patients with Broca's aphasia have lesions that affect frontal regions as well as anterior BA22. These patients would most likely present with textbook agrammatic behavior and would perform better on active than on passive sentences, as did our patients in the anterior BA22 group. Add to that a lesion in the mid-temporal lobe as with our MTG patients, and a more severe deficit could result in the inability to comprehend even simple declarative sentences. Yet another group of patients, some of whom might classify with a Broca's aphasia on the basis of production deficits, could exhibit passing performance on both passive and active voice sentence types, but fail thereafter as did our patients with primarily frontal lesions. Given these variations in lesion patterns, it is reasonable to expect that patients with Broca's aphasia would exhibit different patterns of performance if their lesions involved a different combination of these critical areas. Such discrepancies are most evident in the literature on sentence comprehension in aphasia (Caplan \& Hildebrandt, 1988; Grodzinsky, 2000; Kolk \& van Grunsven, 1985) and bear further investigation in relation to the specific brainbehavior relationships that may predict dissociations in performance.

As a last consideration, we add that a model of brain functioning needs to include both a localization and a distributed processing perspective. As we have indicated, it is not our intention to convey that the five areas described here are restricted, localized regions. Instead, they are each likely to be "nodes" of a distributed network that may indeed support a specific function. When we observe the lesioning of a particular cortical region, we assume the disruption of that local network, with its own set of connections. A complex process such as language comprehension, however, which is made up of many different informational and functional components, must recruit several of these local networks. It is our view that none of the five individual cortical areas identified here is dedicated to sentence processing per se but rather, when brought together, form a network of their own that is specific to language and that supports the comprehension of language. We contend that the field will move closer to understanding the exact nature of this complex network once imaging and lesion studies begin a more fruitful exchange. This is our first contribution to such a discussion.

\section{Acknowledgements}

This research was supported by grants from the National Science Foundation (DBS9207484), the Department of Veterans Affairs Division of Medicine and Surgery, the National Institute of Neurological Disorders and Stroke (P01 NS17778, P01 NS40813) 
and the National Institute of Deafness and Communication Disorders (NIH/NIDCD 2 RO1 DC00216). Portions of this work were presented at the meetings of the Cognitive Neuroscience Society (Dronkers et al., 1994a), the Academy of Aphasia (Dronkers et al., 1994b), and in a working paper entitled "Cortical Areas Underlying the Comprehension of Grammar" (Dronkers et al., 1996). We are grateful to Robert T. Knight for his important contribution in providing lesion reconstructions, to Elizabeth Bates for conceptualizing VLSM, and to Benjamin Russell, Carl Ludy, Juliana Baldo, Jenny Ogar, Bix Swain, Stephen Wilson, Joe Elder and Jary Larsen for their valuable assistance in various aspects of data collection, analysis and preparation of this paper.

Appendix A. CYCLE-R logic: overview of the characteristics of the target and foil line drawings used in each of the CYCLE subtests

\begin{tabular}{|c|c|c|c|c|c|}
\hline \multirow[t]{2}{*}{ Subtest } & \multirow[t]{2}{*}{$\begin{array}{l}\text { Example prompt } \\
\text { sentence }\end{array}$} & \multicolumn{4}{|c|}{$\begin{array}{l}\text { Sample picture contrasts (on hearing prompt sentence, subject meant to identify target } \\
\text { picture from among foils) }\end{array}$} \\
\hline & & Target & Foil 1 & Foil 2 & Foil 3 \\
\hline $\begin{array}{l}\text { Simple } \\
\text { Declaratives (2) }\end{array}$ & $\begin{array}{l}\text { 'The boy is } \\
\text { jumping' }\end{array}$ & $\begin{array}{l}\text { Referent: boy } \\
\text { Action: jumping }\end{array}$ & $\begin{array}{l}\text { Referent: girl } \\
\text { Action: jumping }\end{array}$ & $\begin{array}{l}\text { Referent: boy } \\
\text { Action: standing }\end{array}$ & [no 3rd foil] \\
\hline Possession (3) & $\begin{array}{l}\text { 'The clown } \\
\text { has a balloon' }\end{array}$ & $\begin{array}{l}\text { Referents: clown, } \\
\text { balloon } \\
\text { Action: holding }\end{array}$ & $\begin{array}{l}\text { Referents: girl, } \\
\text { balloon } \\
\text { Action: holding }\end{array}$ & $\begin{array}{l}\text { Referents: } \\
\text { clown, flower } \\
\text { Action: holding }\end{array}$ & [no 3rd foil] \\
\hline $\begin{array}{l}\text { Active Voice } \\
\text { Word Order (4) }\end{array}$ & $\begin{array}{l}\text { 'The girl is } \\
\text { pulling the boy' }\end{array}$ & $\begin{array}{l}\text { Referents: girl, } \\
\text { boy, wagon } \\
\text { Actions: boy sit } \\
\text { in wagon, } \\
\text { girl pull wagon }\end{array}$ & $\begin{array}{l}\text { Referents: girl, } \\
\text { boy, wagon } \\
\text { Actions: girl sit } \\
\text { in wagon, boy } \\
\text { pull wagon }\end{array}$ & $\begin{array}{l}\text { Referents: } \\
\text { dog, boy, wagon } \\
\text { Actions: boy } \\
\text { sit in wagon, } \\
\text { dog pull wagon }\end{array}$ & $\begin{array}{l}\text { Referents: } \\
\text { girl, boy, wagon } \\
\text { Action: girl pull } \\
\text { wagon and boy } \\
\text { pull wagon } \\
\text { together }\end{array}$ \\
\hline $\begin{array}{l}\text { Double } \\
\text { Embedding (4) }\end{array}$ & $\begin{array}{l}\text { 'The clown } \\
\text { that is big } \\
\text { has the balloon }\end{array}$ & $\begin{array}{l}\text { Referents: big clown, } \\
\text { blue balloon }\end{array}$ & $\begin{array}{l}\text { Referents: } \\
\text { small clown, } \\
\text { blue balloon }\end{array}$ & $\begin{array}{l}\text { Referents: } \\
\text { big clown, } \\
\text { red balloon }\end{array}$ & $\begin{array}{l}\text { Referents: small } \\
\text { clown, red balloon }\end{array}$ \\
\hline $\begin{array}{l}\text { Agentless } \\
\text { Passive (4) }\end{array}$ & $\begin{array}{l}\text { that is blue' } \\
\text { 'The girl is } \\
\text { being kicked' }\end{array}$ & $\begin{array}{l}\text { Action: holding } \\
\text { Referents: boy, girl, ball }\end{array}$ & $\begin{array}{l}\text { Action: holding } \\
\text { Referents: } \\
\text { boy, girl, ball }\end{array}$ & $\begin{array}{l}\text { Action: holding } \\
\text { Referents: } \\
\text { girl, ball }\end{array}$ & $\begin{array}{l}\text { Action: holding } \\
\text { [no 3rd foil] }\end{array}$ \\
\hline & & $\begin{array}{l}\text { Action: boy kick girl } \\
\text { [ball in background] }\end{array}$ & $\begin{array}{l}\text { Action: girl kick } \\
\text { boy [ball in } \\
\text { background] } \\
\text { (reverse) }\end{array}$ & $\begin{array}{l}\text { Action: } \\
\text { girl kick ball }\end{array}$ & \\
\hline $\begin{array}{l}\text { Agentive } \\
\text { Passive (5) }\end{array}$ & $\begin{array}{l}\text { 'The girl is being } \\
\text { kicked by the boy' }\end{array}$ & $\begin{array}{l}\text { Referents: boy, girl, ball } \\
\text { Action: boy kick girl } \\
\text { [ball in background] }\end{array}$ & $\begin{array}{l}\text { Referents: } \\
\text { boy, girl, ball } \\
\text { Action: girl } \\
\text { kick boy [ball in } \\
\text { background] } \\
\text { (reverse) }\end{array}$ & $\begin{array}{l}\text { Referents: } \\
\text { clown, girl, ball } \\
\text { Action: } \\
\text { clown kick boy } \\
\text { [ball in } \\
\text { background] }\end{array}$ & $\begin{array}{l}\text { Referents: } \\
\text { clown, boy, ball } \\
\text { Action: boy kick } \\
\text { clown [ball in } \\
\text { background] }\end{array}$ \\
\hline $\begin{array}{l}\text { Subject Relatives } \\
\text { Ending in } \\
\mathrm{N}-\mathrm{V}(7)\end{array}$ & $\begin{array}{l}\text { 'The girl who is } \\
\text { pushing the } \\
\text { boy is happy' }\end{array}$ & $\begin{array}{l}\text { Referents: angry boy, } \\
\text { happy girl, swing }\end{array}$ & $\begin{array}{l}\text { Referents: } \\
\text { happy boy, } \\
\text { angry girl, swing }\end{array}$ & $\begin{array}{l}\text { Referents: } \\
\text { angry boy, } \\
\text { happy girl, swing }\end{array}$ & $\begin{array}{l}\text { Referents: happy } \\
\text { boy, angry girl, } \\
\text { swing }\end{array}$ \\
\hline & & $\begin{array}{l}\text { Actions: boy sit } \\
\text { on swing, } \\
\text { girl push boy } \\
\text { (cause swinging) }\end{array}$ & $\begin{array}{l}\text { Actions: boy sit } \\
\text { on swing, girl push } \\
\text { boy (cause } \\
\text { swinging) }\end{array}$ & $\begin{array}{l}\text { Actions: } \\
\text { girl sit on swing, } \\
\text { boy push girl } \\
\text { (cause swinging) }\end{array}$ & $\begin{array}{l}\text { Actions: girl sit } \\
\text { on swing, } \\
\text { boy push girl } \\
\text { (cause swinging) }\end{array}$ \\
\hline
\end{tabular}




\begin{tabular}{|c|c|c|c|c|c|}
\hline \multirow[t]{2}{*}{ Subtest } & \multirow[t]{2}{*}{$\begin{array}{l}\text { Example prompt } \\
\text { sentence }\end{array}$} & \multicolumn{4}{|c|}{$\begin{array}{l}\text { Sample picture contrasts (on hearing prompt sentence, subject meant to identify target } \\
\text { picture from among foils) }\end{array}$} \\
\hline & & Target & Foil 1 & Foil 2 & Foil 3 \\
\hline \multirow[t]{2}{*}{$\begin{array}{l}\text { Object } \\
\text { Clefting (8) }\end{array}$} & \multirow[t]{2}{*}{$\begin{array}{l}\text { 'It's the boy that } \\
\text { the girl kicks' }\end{array}$} & Referents: boy, girl & Referents: boy, girl & $\begin{array}{l}\text { Referents: } \\
\text { clown, girl }\end{array}$ & $\begin{array}{l}\text { Referents: } \\
\text { clown, boy }\end{array}$ \\
\hline & & Action: girl kick boy & $\begin{array}{l}\text { Action: boy } \\
\text { kick girl }\end{array}$ & $\begin{array}{l}\text { Action: } \\
\text { girl kick clown }\end{array}$ & $\begin{array}{l}\text { Action: boy } \\
\text { kick clown }\end{array}$ \\
\hline \multirow[t]{2}{*}{$\begin{array}{l}\text { Object (O-S) } \\
\text { Relative } \\
\text { Clauses (8) }\end{array}$} & \multirow[t]{2}{*}{$\begin{array}{l}\text { 'The girl is chasing } \\
\text { the clown who is big' }\end{array}$} & $\begin{array}{l}\text { Referents: small girl, } \\
\text { big clown }\end{array}$ & $\begin{array}{l}\text { Referents: big girl, } \\
\text { small clown }\end{array}$ & $\begin{array}{l}\text { Referents: } \\
\text { small girl, } \\
\text { big clown }\end{array}$ & $\begin{array}{l}\text { Referents: big } \\
\text { girl, small clown }\end{array}$ \\
\hline & & Action: girl chase clown & $\begin{array}{l}\text { Action: girl } \\
\text { chase clown }\end{array}$ & $\begin{array}{l}\text { Action: clown } \\
\text { chase girl }\end{array}$ & $\begin{array}{l}\text { Action: clown } \\
\text { chase girl }\end{array}$ \\
\hline \multirow[t]{2}{*}{$\begin{array}{l}\text { Negative } \\
\text { Passive (9) }\end{array}$} & \multirow{2}{*}{$\begin{array}{l}\text { 'The dog is } \\
\text { not being } \\
\text { outrun by the cat' }\end{array}$} & Referents: dog, cat & Referents: dog, cat & $\begin{array}{l}\text { Referents: } \\
\text { dog, cat, mouse }\end{array}$ & [no 3rd foil] \\
\hline & & $\begin{array}{l}\text { Action: dog run } \\
\text { ahead of cat }\end{array}$ & $\begin{array}{l}\text { Action: cat run } \\
\text { ahead of dog }\end{array}$ & $\begin{array}{l}\text { Actions: } \\
\text { cat run ahead } \\
\text { of mouse, } \\
\text { mouse run } \\
\text { ahead of dog }\end{array}$ & \\
\hline \multirow{2}{*}{$\begin{array}{l}\text { Object }(\mathrm{O}-\mathrm{O}) \\
\text { Relatives } \\
\text { with Relativized } \\
\text { Object (9) }\end{array}$} & \multirow{2}{*}{$\begin{array}{l}\text { 'The girl is } \\
\text { kissing the boy } \\
\text { that the clown } \\
\text { is hugging' }\end{array}$} & $\begin{array}{l}\text { Referents: girl, } \\
\text { boy, clown, bench }\end{array}$ & $\begin{array}{l}\text { Referents: girl, } \\
\text { boy, clown, bench }\end{array}$ & $\begin{array}{l}\text { Referents: } \\
\text { girl, boy, } \\
\text { clown, bench }\end{array}$ & $\begin{array}{l}\text { Referents: girl, } \\
\text { boy, clown, bench }\end{array}$ \\
\hline & & $\begin{array}{l}\text { Actions: girl kiss boy; } \\
\text { clown hug boy } \\
\text { [girl stand; boy } \\
\text { and clown sit on bench] }\end{array}$ & $\begin{array}{l}\text { Actions: girl } \\
\text { kiss boy; boy hug } \\
\text { clown [girl stand; } \\
\text { boy and clown } \\
\text { sit on bench] }\end{array}$ & $\begin{array}{l}\text { Actions: } \\
\text { girl kiss clown; } \\
\text { boy hug clown } \\
\text { [girl stand; } \\
\text { boy and clown } \\
\text { sit on bench] }\end{array}$ & $\begin{array}{l}\text { Actions: boy kiss } \\
\text { girl; clown hug } \\
\text { girl [boy stand; } \\
\text { girl and clown } \\
\text { sit on bench] }\end{array}$ \\
\hline
\end{tabular}

\section{References}

Adolphs, R., Damasio, H., Tranel, D., Cooper, G., \& Damasio, A. R. (2000). A role for somatosensory cortices in the visual recognition of emotion as revealed by three-dimensional lesion mapping. Journal of Neuroscience, 20(7), 2583-2690.

Baddeley, A. D. (1986). Working memory. Oxford: Oxford University Press.

Baldo, J., \& Dronkers, N. (1999). Verbal and non-verbal short-term memory in patients with conduction aphasia and prefrontal cortex lesions. Brain and Language, 69(3), 475-478.

Bates, E., Wilson, S., Saygin, A. P., Dick, F., Sereno, M., Knight, R. T., \& Dronkers, N. F. (2003). Voxel-based lesion-symptom mapping. Nature Neuroscience, 6(5), 448-450.

Benson, D. F., \& Ardila, A. (1996). Aphasia: a clinical perspective. New York: Oxford University Press.

Berndt, R. S., \& Caramazza, A. (1980). A redefinition of the syndrome of Broca's aphasia: implications for a neuropsychological model of language. Applied Psycholinguistics, 1, 225-278.

Binder, J. R., Frost, J. A., Hammeke, T. A., Cox, R. W., Rao, S. M., \& Prieto, T. (1997). Human brain language areas identified by functional magnetic resonance imaging. Journal of Neuroscience, 17(1), 353-362.

Binder, J. R., Frost, J. A., Hammeke, T. A., Rao, S. M., \& Cox, R. W. (1996). Function of the left planum temporale in auditory and linguistic processing. Brain, 119(Pt 4), 1239-1247.

Binkofski, F., Amunts, K., Stephan, K. M., Posse, S., Schormann, T., Freund, H. J., Zilles, K., \& Seitz, R. J. (2000). Broca's region subserves imagery of motion: a combined cytoarchitectonic and fMRI study. Human Brain Mapping, 11(4), 273-285. 
Broca, P. (1861). Remarques sur le siège de la faculté du langage articulé, suivies d'une observation d'aphémie (perte de la parole). Bulletins de la Société d'Anatomie (Paris), 2e serie, 6, 330-357.

Broca, P. (1864). Sur les mots aphemie, aphasie et aphrasie; Lettre a M. le Professeur Trousseau. Gazette des Hopitaux, 23.

Cabeza, R., \& Nyberg, L. (2000). Imaging cognition II: an empirical review of 275 PET and fMRI studies. Journal of Cognitive Neuroscience, 12(1), 1-47.

Caplan, D. (1992). Language: structure, processing, and disorders. Cambridge, MA: MIT Press.

Caplan, D., Baker, C., \& Dehaut, F. (1985). Syntactic determinants of sentence comprehension in aphasia. Cognition, 21(2), 117-175.

Caplan, D., \& Hildebrandt, N. (1988). Disorders of syntactic comprehension. Cambridge, MA: MIT Press.

Caplan, D., Hildebrandt, N., \& Makris, N. (1996). Location of lesions in stroke patients with deficits in syntactic processing in sentence comprehension. Brain, 119, 933-949.

Caplan, D., \& Waters, G. S. (1999). Verbal working memory and sentence comprehension. Behavioral and Brain Sciences, 22(1), 77-126.

Cappa, S. F., Perani, D., Schnur, T., Tettamanti, M., \& Fazio, F. (1998). The effects of semantic category and knowledge type on lexical-semantic access: a PET study. NeuroImage, 8, 350-359.

Caramazza, A., \& Zurif, E. B. (1976). Dissociation of algorithmic and heuristic processes in language comprehension: evidence from aphasia. Brain and Language, 3, 572-582.

Chao, L. L., \& Knight, R. T. (1998). Contribution of human prefrontal cortex to delay performance. Journal of Cognitive Neuroscience, 10(2), 167-177.

Curtiss, S., \& Yamada, J (1988). Curtiss-Yamada Comprehensive Language Evaluation. Unpublished test, UCLA.

Damasio, H., Grabowski, T. J., Tranel, D., Hichwa, R. D., \& Damasio, A. (1996). A neural basis for lexical retrieval. Nature, 380, 499-505.

DeArmond, S. J., Fusco, M., \& Dewey, M. (1976). Structure of the human brain (2nd ed.). New York: Oxford University Press.

D’Esposito, M., Postle, B. R., Ballard, D., \& Lease, J. (1999). Maintenance versus manipulation of information held in working memory: an event-related fMRI study. Brain and Cognition, 41, 66-86.

Dronkers, N. F. (1996). A new brain region for coordinating speech articulation. Nature, 384(6605), 159-161.

Dronkers, N. F., Redfern, B. B., \& Knight, R. T. (2000). The neural architecture of language disorders. In M. S. Gazzaniga (Ed.), The new cognitive neurosciences (pp. 949-958). Cambridge, MA: MIT Press.

Dronkers, N. F., Redfern, B. B., \& Ludy, C. (1995). Lesion localization in chronic Wernicke's aphasia. Brain and Language, 51(1), 62-65.

Dronkers, N. F., Redfern, B. B., Ludy, C., \& Baldo, J. (1998). Brain regions associated with conduction aphasia and echoic rehearsal. Journal of the International Neuropsychological Society, 4, 23-24.

Dronkers, N. F., Shapiro, J. K., Redfern, B., \& Knight, R. T. (1992). The role of Broca's area in Broca's aphasia. Journal of Clinical and Experimental Neuropsychology, 14, 52-53.

Dronkers, N. F., Wilkins, D. P., Van Valin, R., Jr., Redfern, B., \& Jaeger, J (1994a). Neural mechanisms of morphosyntactic comprehension deficits. Paper presented at the annual meeting of the Cognitive Neuroscience Society, San Francisco, CA.

Dronkers, N. F., Wilkins, D. P., Van Valin, R., Jr., Redfern, B., \& Jaeger, J. (1994b). A reconsideration of the brain areas involved in the disruption of morphosyntactic comprehension. Brain and Language, 47(3), $461-463$.

Dronkers, N. F., Wilkins, D. P., Van Valin, R., Jr., Redfern, B., \& Jaeger, J. (1996). Cortical areas underlying the comprehension of grammar. Working Papers from the Center for Aphasia and Related Disorders, 1(1).

Frey, R. T., Woods, D. L., Knight, R. T., Scabini, D., \& Clayworth, C. (1987). Defining functional areas with averaged CT scans. Society for Neuroscience Abstracts, 13, 1266.

Friederici, A. (2002). Towards a neural basis of auditory sentence processing. Trends in Cognitive Sciences, 6 , 78-84.

Friederici, A., Meyer, M., \& von Cramon, D. Y. (2000). Auditory language comprehension: an event-related fMRI study on the processing of syntactic and lexical information. Brain and Language, 74(2), 289-300.

Friederici, A., \& von Cramon, D. Y. (2000). Syntax in the brain: linguistic versus neuroanatomical specificity. Behavioral and Brain Sciences, 23(1), 32-33. 
Friedman, L., Kenny, J. T., Wise, A. L., Wu, D., Stuve, T. A., Miller, D. A., Jesberger, J. A., \& Lewin, J. S. (1998). Brain activation during silent word generation evaluated with functional MRI. Brain and Language, 64(2), 231-256.

Friedrich, F. J., Egly, R., Rafal, R. D., \& Beck, D. (1998). Spatial attention deficits in humans: a comparison of superior parietal and temporal-parietal junction lesions. Neuropsychology, 12(2), 193-207.

Goodglass, H. (1993). Understanding aphasia. San Diego, CA: Academic Press.

Grady, C. L., Van Meter, J. W., Maisog, J. M., Pietrini, P., Krasuski, J., \& Rauschecker, J. P. (1997). Attentionrelated modulation of activity in primary and secondary auditory cortex. NeuroReport, 8(11), 2511-2516.

Grodzinsky, Y. (2000). The neurology of syntax: language use without Broca's area. Behavioral and Brain Sciences, 23, 1-71.

Hagoort, P., Brown, C. M., \& Osterhout, L. (2000). The neurocognition of syntactic processing. In C. M. Brown, \& P. Haggort (Eds.), The neurocognition of language (pp. 273-316). New York: Oxford University Press.

Hart, J., \& Gordon, B. (1990). Delineation of single-word semantic comprehension deficits in aphasia, with anatomical correlation. Annals of Neurology, 27, 226-231.

Hickok, G., \& Poeppel, D (this issue). Dorsal and ventral streams: a framework for understanding the functional anatomy of language. Cognition.

Howard, D., Patterson, K., Wise, R., Brown, W. D., Friston, K., Weiller, C., \& Frackowiak, R. (1992). The cortical localization of the lexicons. Positron emission tomography evidence. Brain, 115(Pt 6), 1769-1782.

Indefrey, P., \& Levelt, W. J. M. (2000). The neural correlates of language production. In M. S. Gazzaniga (Ed.), The new cognitive neurosciences (2nd ed.) (pp. 845-865). Cambridge, MA: MIT Press.

Jonides, J., Schumacher, E. H., Smith, E. E., Koeppe, R. A., Awh, E., Reuter-Lorenz, P. A., Marshuetz, C., \& Willis, C. R. (1998). The role of parietal cortex in verbal working memory. Journal of Neuroscience, 18(13), 5026-5034.

Just, M. A., Carpenter, P. A., Keller, T. A., Eddy, W. F., \& Thulborn, K. R. (1996). Brain activation modulated by sentence comprehension. Science, 274, 114-116.

Kaan, E., \& Swaab, T. Y. (2002). The brain circuitry of syntactic comprehension. Trends in Cognitive Science, $6(8), 350-356$.

Kertesz, A. (1979). Aphasia and associated disorders: taxonomy, localization and recovery. New York: Grune and Stratton.

Kertesz, A. (1982). Western Aphasia Battery. New York: Grune and Stratton.

Knight, R. T., Scabini, D., Woods, D. L., \& Clayworth, C. (1988). The effects of lesions of superior temporal gyrus and inferior parietal lobe on temporal and vertex components of the human AEP. Electroencephalography and Clinical Neurophysiology, 70, 499-509.

Kolk, H. H., \& van Grunsven, M. (1985). Agrammatism as a variable phenomenon. Cognitive Neuropsychology, 2, 347-384.

Mazoyer, B. M., Tzourio, N., Frak, V., Syrota, A., Murayama, N., Levrier, O., Salamon, G., Dehaene, S., Cohen, L., \& Mehler, J. (1993). The cortical representation of speech. Journal of Cognitive Neuroscience, 5(4), 467-479.

Meyer, M., Alter, K., Friederici, A. D., Lohmann, G., \& von Cramon, D. Y. (2002). FMRI reveals brain regions mediating slow prosodic modulations in spoken sentences. Human Brain Mapping, 17(2), $73-88$.

Miyake, A., Carpenter, P. A., \& Just, M. A. (1994). A capacity approach to syntactic comprehension disorders: making normal adults perform like aphasic patients. Cognitive Neuropsychology, 11, 671-717.

Mohr, J. P. (1976). Broca's area and Broca's aphasia. In H. Whitaker, \& H. Whitaker (Eds.), (1) (pp. 201-233). Studies in neurolinguistics, New York: Academic Press.

Mohr, J. P., Pessin, M. S., Finkelstein, S., Funkenstein, H. H., Duncan, G. W., \& Davis, K. R. (1978). Broca aphasia: pathologic and clinical. Neurology, 28, 311-324.

Muller, R. A., Rothermel, R. D., Behen, M. E., Muzik, O., Mangner, T. J., \& Chugani, H. T. (1997). Receptive and expressive language activations for sentences: a PET study. NeuroReport, 8(17), 3767-3770.

Naeser, M. A., \& Hayward, R. W. (1978). Lesion localization in aphasia with cranial computed tomography and the Boston Diagnostic Aphasia Exam. Neurology, 28, 545-551.

Perani, D., Dehaene, S., Grassi, F., Cohen, L., Cappa, S. F., Dupoux, E., Fazio, F., \& Mehler, J. (1996). Brain processing of native and foreign languages. NeuroReport, 7(15-17), 2439-2444. 
Petrides, M. (1994). Frontal lobes and working memory: evidence from investigations of the effects of cortical excisions in nonhuman primates. In F. Boller, \& J. Grafman (Eds.), (9) (pp. 59-82). Handbook of neuropsychology, Amsterdam: Elsevier.

Pugh, K. R., Shaywitz, B. A., Shaywitz, S. E., Constable, R. T., Skudlarski, P., Fulbright, R. K., Bronen, R. A., Shankweiler, D. P., Katz, L., Fletcher, J. M., \& Gore, J. C. (1996). Cerebral organization of component processes in reading. Brain, 119(Pt 4), 1221-1238.

Saffran, E. M., \& Marin, O. S. (1975). Immediate memory for word lists and sentences in a patient with deficient auditory short-term memory. Brain and Language, 2(4), 420-433.

Schlosser, M. J., Aoyagi, N., Fulbright, R. K., Gore, J. C., \& McCarthy, G. (1998). Functional MRI studies of auditory comprehension. Human Brain Mapping, 6(1), 1-13.

Schwartz, M. F., Saffran, E. M., \& Marin, O. (1980). The word order problem in agrammatism I: comprehension. Brain and Language, 10, 249-262.

Stowe, L. A., Broere, C. A., Paans, A. M., Wijers, A. A., Mulder, G., Vaalburg, W., \& Zwarts, F. (1998). Localizing components of a complex task: sentence processing and working memory. NeuroReport, 9(13), 2995-2999.

Stromswold, K., Caplan, D., Alpert, N., \& Rauch, S. (1996). Localization of syntactic comprehension by positron emission tomography. Brain and Language, 52, 452-473.

Talairach, J., \& Tournoux, P. (1988). Co-planar stereotaxic atlas of the human brain. New York: Thieme Medical.

Warburton, E., Wise, R., Price, C., Weiller, C., Hadar, U., Ramsey, S., \& Frackowiak, R. (1996). Noun and verb retrieval by normal subjects. Studies with PET. Brain, 119, 159-179.

Warrington, E. K., \& Shallice, T. (1969). The selective impairment of auditory verbal short-term memory. Brain, 92(4), 885-896.

Wise, R., Chollet, F., Hadar, U., Friston, K., Hoffner, E., \& Frackowiak, R. (1991). Distribution of cortical neural networks involved in word comprehension and word retrieval. Brain, 114, 1803-1817.

Zurif, E. B., Caramazza, A., \& Meyerson, R. (1972). Grammatical judgements of agrammatic aphasics. Neuropsychologia, 10, 405-417. 